\title{
Analysis of Langmuir Probe Characteristics for Measurement of Plasma Parameters in RF Discharge Plasmas
}

\author{
Kohgi Kato, Satoru Iizuka* \\ Department of Electrical Engineering, Graduate School of Engineering, Tohoku University, \\ Sendai, Japan \\ Email: ^iizuka@ecei.tohoku.ac.jp
}

How to cite this paper: Kato, K. and Iizuka, S. (2016) Analysis of Langmuir Probe Characteristics for Measurement of Plasma Parameters in RF Discharge Plasmas. Journal of Applied Mathematics and Physics, 4, 1811-1836.

http://dx.doi.org/10.4236/jamp.2016.49185

Received: July 13, 2016

Accepted: September 26, 2016

Published: September 29, 2016

Copyright $\odot 2016$ by authors and Scientific Research Publishing Inc. This work is licensed under the Creative Commons Attribution International License (CC BY 4.0).

http://creativecommons.org/licenses/by/4.0/ (c) (i) Open Access

\begin{abstract}
A simple method for measuring RF plasma parameters by means of a DC-biased Langmuir probe is developed. The object of this paper is to ensure the reliability of this method by using the other methods with different principles. First, Langmuir probe current $I_{\mathrm{e}}$ response on RF voltage $V_{\mathrm{p} 1}$ superimposed to DC $V_{\mathrm{p}}$ biased probe was examined in DC plasmas. Next, probe current response of DC biased probe in RF plasmas was studied and compared with the first experiment. The results were confirmed by using an emissive prove method, an ion acoustic wave method, and a square pulse response method. The method using a simple Langmuir probe is useful and convenient for measuring electron temperature $T_{\mathrm{e}}$, electron density $n_{\mathrm{e}}$, time-averaged space potential $V_{\mathrm{s} 0}$, and amplitude of space potential oscillation $V_{\mathrm{s} 1}$ in RF plasmas with a frequency of the order of $f_{\mathrm{pi}}<f<f_{\mathrm{pe}} / 10$.
\end{abstract}

\section{Keywords}

Langmuir Probe, Radio Frequency Discharge, RF Plasma, Plasma Parameters

\section{Introduction}

During the past 50 years, various techniques have been developed to determine plasma parameters in RF discharge plasmas using a Langmuir probe [1]-[5], an RF-driven probe [6]-[8], a compensated RF-driven probe [9]-[11], a tuned probe [12] [13], and optical method [14] [15]. When an RF signal same as the phase and amplitude of space potential in RF (13.56 MHz) discharge plasmas is applied to a probe, RF potential between the probe and the plasma can be removed. In this case, a characteristic curve 
similar to a curve of DC discharge plasma is provided by this technique. By using this principle Braithwaite [6], Paranjpe [13], and others carried out detailed experiments and reported the experimental results [6]-[13]. However, these techniques are complicated and troublesome for measuring the plasma parameters. For example, the driven probe method needs a phase controller, an attenuator, an oscilloscope, etc., and the tuned probe technique requires a tuning network, a low-path filter, and so forth for obtaining probe current and voltage $I_{\mathrm{p}}-V_{\mathrm{p}}$ characteristics. In addition, these procedures need to lock the probe potential to the phase of oscillation of plasma space potential at each time whenever experimental conditions are altered; namely, gas pressure, electric power, probe position, and so on. Therefore, the methods mentioned above are rather difficult and impractical.

The same electric current flows in a probe circuit in the following two cases. The first case is that the probe potential is constant, and space potential oscillates in the plasma. The second case is that space potential is constant, and probe potential oscillates in the plasma. In other words, both cases are totally equivalent for an electric circuit. In 1963, by using a numerical computation Boschi [3] obtained the time-averaged probe characteristic curves of a DC plasma in which a probe potential vibrated sinusoidally. If the electron distribution function is Maxwellian and the probe voltage $V_{\mathrm{p}}(t)$ in a DC plasma is oscillating sinusoidally with a frequency $f$ and an amplitude $V_{\mathrm{p} 1}$ around the probe bias voltage $V_{\mathrm{p}}$, i.e.

$$
V_{\mathrm{p}}(t)=V_{\mathrm{p}}+V_{\mathrm{p} 1} \sin \omega t
$$

Here, $\omega=2 \pi f$ is angular frequency. For probe bias $V_{\mathrm{p}}<V_{\mathrm{s} 0}-V_{\mathrm{p} 1}$, where electrons are always retarded, the electron current density $j_{\mathrm{p}}(t)$ flowing into the probe can be expressed as follows [3] [4]:

$$
\begin{aligned}
j_{\mathrm{p}}(t) & =j_{\mathrm{e} 0} \exp \left[-\frac{\mathrm{e}\left(V_{\mathrm{s} 0}-V_{\mathrm{p}}-V_{\mathrm{p} 1} \sin \omega t\right)}{k T_{\mathrm{e}}}\right]-j_{\mathrm{i} 0} \\
& =j_{\mathrm{e} 0} \exp \left[-\frac{\mathrm{e}\left(V_{\mathrm{s} 0}-V_{\mathrm{p}}\right)}{k T_{\mathrm{e}}}\right] \exp \left[\frac{\mathrm{e} V_{\mathrm{p} 1}}{k T_{\mathrm{e}}} \sin \omega t\right]-j_{\mathrm{i} 0} .
\end{aligned}
$$

Here, $V_{\mathrm{s} 0}$ is the space potential of DC plasma. The time-averaged probe characteristic $\left\langle j_{\mathrm{p}}\right\rangle$ can be expressed as follows:

$$
\left\langle j_{\mathrm{p}}\right\rangle=j_{\mathrm{e} 0} \exp \left[-\frac{\mathrm{e}\left(V_{\mathrm{s} 0}-V_{\mathrm{p}}\right)}{k T_{\mathrm{e}}}\right] I_{0}\left(\frac{\mathrm{e} V_{\mathrm{p} 1}}{k T_{\mathrm{e}}}\right)-j_{\mathrm{i} 0} .
$$

where $j_{\mathrm{e} 0}$ and $j_{\mathrm{i} 0}$ are saturated currents of electrons and ions for a DC plasma. $I_{0}$ is the zeroth order modified Bessel function. If $\Delta V$ is defined by the following equation, i.e.

$$
e \Delta V=k T_{\mathrm{e}} \ln \left[I_{0}\left(\frac{e V_{\mathrm{p} 1}}{k T_{\mathrm{e}}}\right)\right],
$$

Equation (5) can be derived from Equations (1)-(4). 


$$
\left\langle j_{\mathrm{p}}\right\rangle=j_{\mathrm{e} 0} \exp \left[-\frac{e\left(V_{\mathrm{s} 0}-V_{\mathrm{p}}-\Delta V\right)}{k T_{\mathrm{e}}}\right]-j_{\mathrm{i} 0} .
$$

Equation (5) shows that the time-averaged probe characteristic curve shifts in parallel to more negative value $\Delta V$ than a case of $V_{\mathrm{p} 1}=0 \mathrm{~V}$, so that the electron temperature $T_{\mathrm{e}}$ is constant regardless of the frequency $f$ and the amplitude $V_{\mathrm{p} 1}$. In the case of $V_{\mathrm{s} 0}-V_{\mathrm{p} 1}<V_{\mathrm{p}}<V_{\mathrm{s} 0}+V_{\mathrm{p} 1}$, because the probe characteristic curve was not expressed in a numerical formula, it was derived by using a computer [Figure 2 in Ref. 3]. As a result, following conclusions were derived.

(A) Inflection points appear at two places of $V_{\mathrm{s} 0} \pm V_{\mathrm{p} 1}$ on the time-averaged probe characteristic curve.

(B) The floating potential $V_{\mathrm{f}}$ is unrelated to the applied frequency $f$, and moves to the low potential side by $\Delta V$ as the amplitude $V_{\mathrm{p} 1}$ becomes large.

(C) The electron temperature $T_{\mathrm{e}}$ is constant regardless of the frequency $f$ and the amplitude $V_{\mathrm{p} 1}$.

He obtained the time-averaged probe characteristic curves where the sinusoidal voltage from $10 \mathrm{~Hz}$ to $10 \mathrm{MHz}$ was applied to a probe in DC discharge plasma. As a result, the experimental data well agreed with the theory concerning to the items (B) and (C). Both items suggest that electron temperature can be also obtained from a time-averaged characteristic curve of RF discharge plasma. Garscadden [1] also measured how a probe characteristic curve was changed by applying a sinusoidal potential covering from 50 $\mathrm{Hz}$ to $500 \mathrm{~Hz}$ to the probe. As a result, the curve as it was expected by Equation (5) was provided [see Figure 2 in Ref. 1].

In this paper investigations of the effects of RF potential oscillation on the Langmuir probe characteristic $I_{\mathrm{p}}-V_{\mathrm{p}}$ curve are described, and a simple method for interpreting the plasma parameter data is presented. This method is based on using a time-averaged Langmuir probe $I_{\mathrm{p}}-V_{\mathrm{p}}$ characteristic, and is very simple, because almost the same probe circuit which is used for DC discharge plasmas can be used.

\section{Experiments Using DC Discharge Plasma}

\subsection{Experimental Device for Applying a Sinusoidal Voltage to a Probe}

The experimental device and measurement system for obtaining a probe characteristic curve is shown in Figure 1(a). The discharge chamber, $23 \mathrm{~cm}$ in diameter and $50 \mathrm{~cm}$ in length, is situated in a stainless steel vacuum chamber of $60 \mathrm{~cm}$ in diameter and $100 \mathrm{~cm}$ long, which is evacuated to a pressure of $10^{-3} \mathrm{~Pa}$ by using a diffusion pump and a rotary pump. A probe tip has a plane circular surface of $3.5 \mathrm{~mm}$ in diameter and is spotwelded to a copper wire lead of a $50-\Omega$ semi-rigid coaxial cable which is sleeved within a glass tube. This probe, collecting electrons on both sides, is put at the position of a radius of $3 \mathrm{~cm}$. A magnetic field $B\left(20 \times 10^{-4} \mathrm{~T}\right)$ is added so that the high energy-tail electrons from a cathode of $2 \mathrm{~cm}$ in diameter cannot arrive at the probe.

The probe is biased by two dry batteries of $90 \mathrm{~V}$ in order to prevent $50 \mathrm{~Hz}$ signal from spreading over the probe and discharge circuit. In addition to a DC bias voltage $V_{\mathrm{p}}$, a 


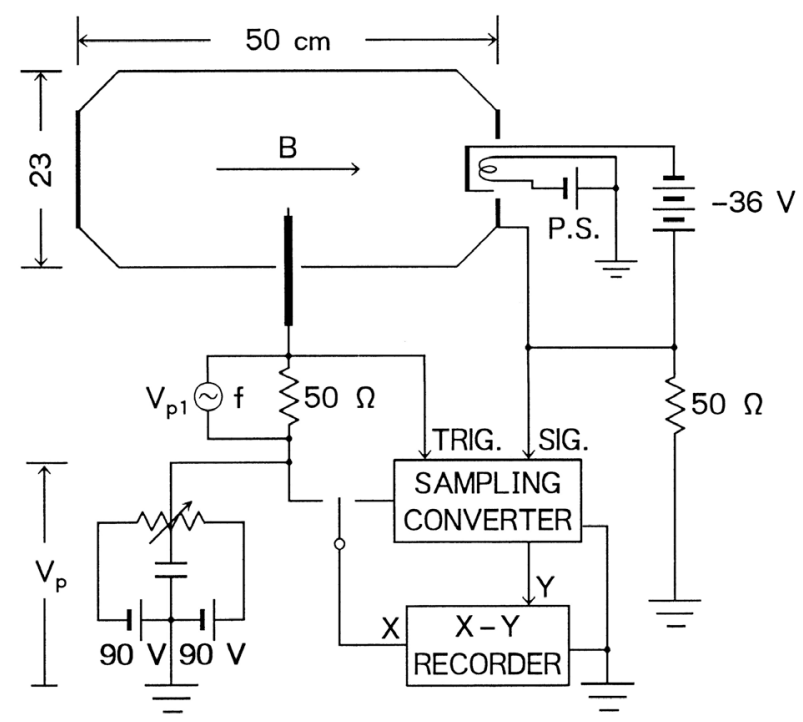

(a)

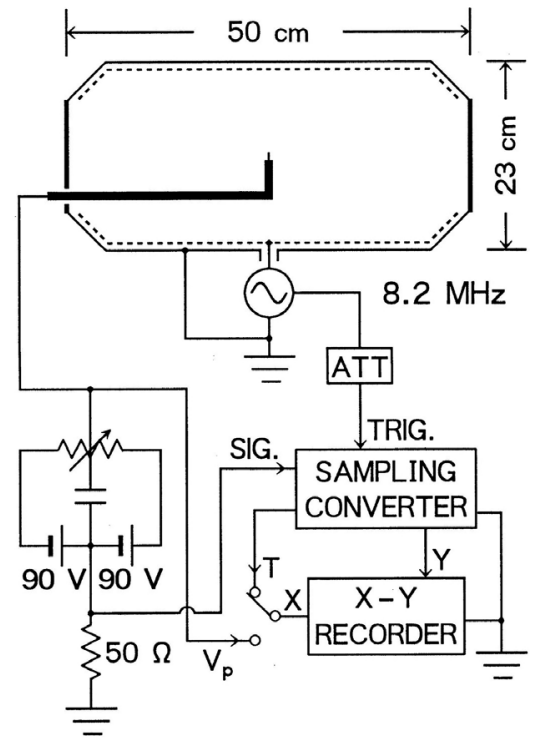

(b)

Figure 1. Experimental device and electric circuit for (a) DC and (b) RF discharges and for obtaining time-averaged and time-resolved probe characteristic curves with a sampling convertor.

sinusoidal voltage with amplitude $V_{\mathrm{p} 1}$ is applied to the probe by a function generator which gives signals whose frequency $f$ is controlled from $30 \mathrm{kHz}$ to $10 \mathrm{MHz}$. An argon plasma is generated at a pressure of $0.133 \mathrm{~Pa}$ by applying a discharge voltage $V_{\mathrm{D}} \quad(=-36$ $\mathrm{V})$ to a disc cathode ( $\mathrm{BaO}$ cathode) with respect to the cylindrical electrode (anode) which is connected to a $50 \Omega$ resistor. For the DC discharge three storage batteries were employed to prevent $50 \mathrm{~Hz}$ signal from spreading over the probe and discharge circuit. Before drawing a characteristic $I_{\mathrm{p}}-V_{\mathrm{p}}$ curve the probe is cleaned by biasing to $-100 \mathrm{~V}$ in order to remove surface contamination by Ar ion bombardment. A probe characte- 
ristic curve is drawn on an $X-Y$ recorder for measuring plasma parameters. The low-pass filter (LPF) with blocking frequency of $10 \mathrm{kHz}$ is used to allow DC current into the $\mathrm{Y}$ terminal of the $X-Y$ recorder.

In order to receive a high frequency signal from plasma exactly next four items [16] [17] are considered.

1) A $50 \Omega$ metal film resistor is put between a discharge tube and the ground. This resistor is used to match the characteristic impedance of the $50-\Omega$ coaxial cable. The signal from plasma is received by this resistor.

2) Three lead storage batteries connected tandemly for DC discharge is put on a wooden desk. This is because the capacitance does not evolve between the batteries and the earth.

3) The power supply (P.S.) for heating the barium oxide $(\mathrm{BaO})$ cathode which diameter is $2 \mathrm{~cm}$ is separated from the measurement circuit.

4) Sinusoidal voltage provided by a function generator is applied to a probe using a $50 \Omega$ metal film resistor instead of a coupling transformer [2].

\subsection{Time-Averaged Probe Characteristic Curves}

Time-averaged probe $I_{\mathrm{p}}-V_{\mathrm{p}}$ characteristics, which have been already reported in Refs. [18] [19], are shown in Figure 2. All of characteristics shown by dotted lines are the same $I_{\mathrm{p}}-V_{\mathrm{p}}$ curves obtained at $V_{\mathrm{p} 1}=0 \mathrm{~V}$. From a semi-log plot of their electron currents $I_{\mathrm{e}}$ space potential $V_{\mathrm{s} 0}=5.6 \mathrm{~V}$, electron temperature $T_{\mathrm{e}}=1.5 \mathrm{eV}$ and electron density $n_{\mathrm{e}}=2.4 \times 10^{9} \mathrm{~cm}^{-3}$ are gotten, so that ion plasma frequency is $f_{\mathrm{pi}}=1.6 \mathrm{MHz}$, which is given by $f_{\mathrm{pi}}=33 \times \sqrt{n_{\mathrm{e}}} \mathrm{Hz}$ for Ar. Time-averaged $I_{\mathrm{p}}-V_{\mathrm{p}}$ curves at $f=30$ $\mathrm{kHz}, 0.6 \mathrm{MHz}$, and $10 \mathrm{MHz}$ for $V_{\mathrm{p} 1}=7.5 \mathrm{~V}$ are also shown by solid lines in Figures 2(a)-(c), respectively. For $f=30 \mathrm{kHz}<f_{\mathrm{pi}} / 10$ there appear two inflection points on the $I_{\mathrm{p}}-V_{\mathrm{p}}$ curve (solid line) at $V_{\mathrm{p}}=V_{\mathrm{s} 0} \pm V_{\mathrm{p} 1}$ as pointed by long arrows (see also Refs. 3, 4 and 5). In this case, the same $T_{\mathrm{e}}$ from the two $I_{\mathrm{p}}-V_{\mathrm{p}}$ curves as expressed by Equation (5) can be obtained. However, for $f=0.6 \mathrm{MHz}<f_{\mathrm{pi}}$ the inflection points become
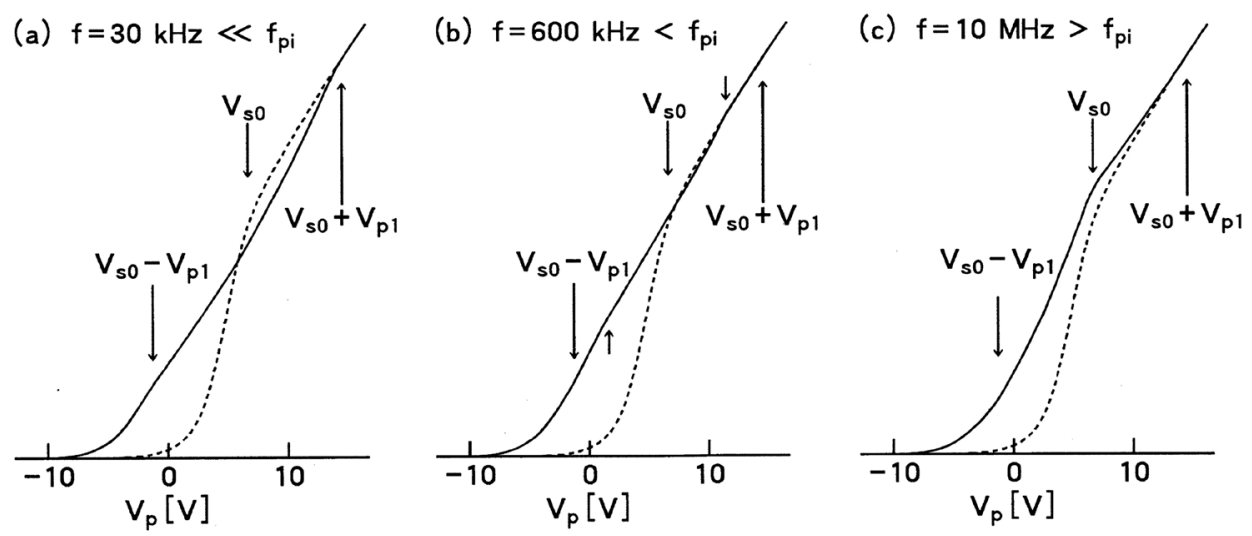

Figure 2. Time-averaged $I_{\mathrm{p}}-V_{\mathrm{p}}$ characteristics (dotted lines: $V_{\mathrm{p} 1}=0 \mathrm{~V}$, solid lines: $V_{\mathrm{p} 1}=7.5 \mathrm{~V}$ ) for (a) $f=30 \mathrm{kHz}$, (b) $f=0.6 \mathrm{MHz}$, and (c) $f=10 \mathrm{MHz}$. Here, ion plasma frequency $f_{\mathrm{pi}}$ is $1.6 \mathrm{MHz}$. 
not clear as pointed by short arrows, and their potentials seem to approach to the potential $V_{\mathrm{s} 0}$. For $f=10 \mathrm{MHz}>f_{\mathrm{pi}}$ the potentials of these points are completely shifted to $V_{\mathrm{s} 0}$ as shown in Figure 2(c). These phenomena are different from the results reported in Refs. 3, 4 and 5. On the other hand, one can see that in the regime $V_{\mathrm{p}}<V_{\mathrm{s} 0}-V_{\mathrm{p} 1}$ three time-averaged curves shown solid lines are the same form in all cases in Figure 2. Therefore, it can be confirmed that electron temperature $T_{\mathrm{e}}$ provided from the range $V_{\mathrm{p}}<V_{\mathrm{s} 0}-V_{\mathrm{p} 1}$ of the time-averaged curve (solid line) gives the same value without depending on the applied frequency $f$ as described in the item (C). It is also confirmed that $T_{\mathrm{e}}$ is independent of the amplitude $V_{\mathrm{p} 1}$.

\subsection{Frequency Dependency of Inflection Points}

Figure 3 shows frequency dependency of potential difference $V_{\text {pd }}$ between two inflection points observed on a time-averaged $I_{\mathrm{p}}-V_{\mathrm{p}}$ curve, as described in Figure 2 for $V_{\mathrm{p} 1}=7.5 \mathrm{~V}$. In the case of $f<f_{\mathrm{pi}} / 10, V_{\mathrm{pd}}$ has a constant value $2 V_{\mathrm{p} 1}=15.0 \mathrm{~V}$ as shown in Refs. [1] and [3]. In the case of $f_{\mathrm{pi}} / 10<f<f_{\mathrm{pi}}$, however, $V_{\mathrm{pd}}$ becomes small as frequency rises. Finally, in the case of $f>f_{\mathrm{pi}}=1.6 \mathrm{MHz}, V_{\mathrm{pd}}$ is equal to $0 \mathrm{~V}$. This phenomenon occurs due to the slow motion of ions, being not able to follow the change of the high-frequency electric field within the probe-plasma sheath [20]. The phenomena to occur at frequency more than $f_{\mathrm{pi}} / 10$ are different from the theoretical results reported in References [1]-[3].

Figure 4 shows semi-log plots of time-averaged electron currents shown in Figure 2(c). In the case of $V_{\mathrm{p} 1}=7.5 \mathrm{~V}$, two inflection points appear on the semi-log plot of the time-averaged electron current $I_{\mathrm{e}}-V_{\mathrm{p}}$, as shown by opened circles. The potential of the upper one is equal to the DC plasma space potential $V_{\mathrm{s} 0}=5.6 \mathrm{~V}$. The potential of

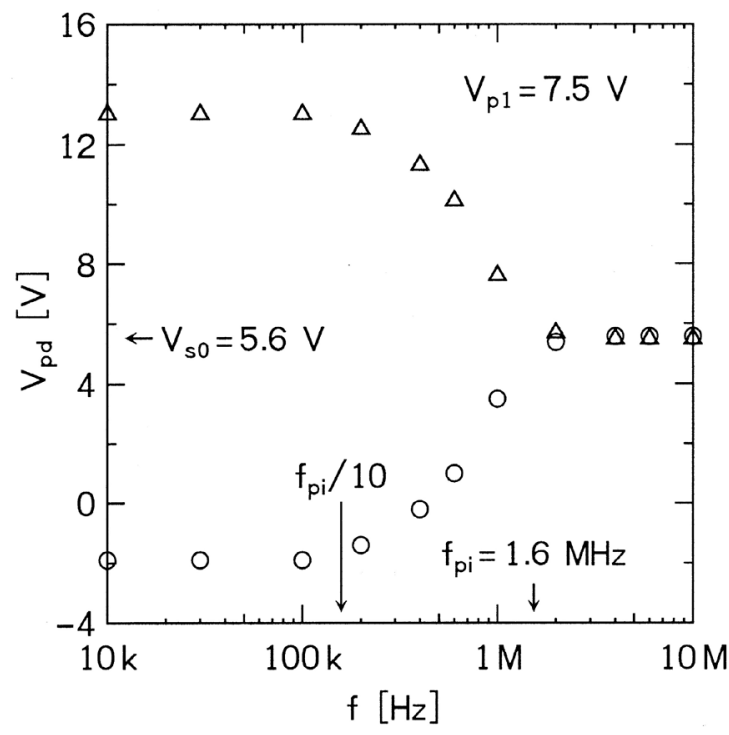

Figure 3. Frequency $(f)$ dependency of potential difference $V_{\mathrm{pd}}$ between upper and lower inflection points on the time-averaged probe characteristic curve. 


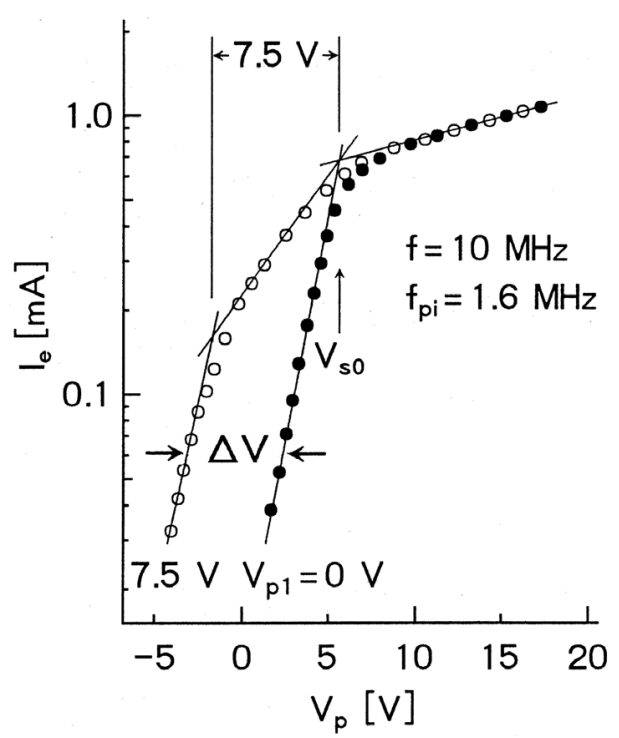

Figure 4. Semi-log plots of the time-averaged probe characteristic $I_{\mathrm{e}}-V_{\mathrm{p}}$ curve shown in Figure 2(c). Closed and open circles correspond to the case of $V_{\mathrm{p} 1}=0 \mathrm{~V}$ and $7.5 \mathrm{~V}$, respectively.

the lower one is equal to $-1.9 \mathrm{~V}$, which is also equal to $V_{\mathrm{s} 0}-V_{\mathrm{p} 1}$. In other words, the potential difference between these points equals the amplitude $V_{\mathrm{p} 1}=7.5 \mathrm{~V}$ of the RF voltage applied to the probe. In addition, the electron saturation current $I_{\text {sat }}$ at the upper inflection point at $V_{\mathrm{s} 0}$ is almost equal to that in the case of $V_{\mathrm{p} 1}=0 \mathrm{~V}$ (dotted line). Further, the same electron temperature of $T_{\mathrm{e}}=1.5 \mathrm{eV}$ can be estimated from two parallel straight-lines fitting to the semi-log plots in the retarding potential range $V_{\mathrm{p}}<V_{\mathrm{s} 0}-V_{\mathrm{p} 1}$. Therefore, It was confirmed that Equation (5) could be even applied to the case of the high frequencies more than $f_{\mathrm{pi}}$. Therefore, all plasma parameters including $V_{\mathrm{p} 1}$ can be measured from the semi-log plots shown by opened circles in Figure 4.

The potential difference $V_{\text {dif }}$ between upper and lower inflection points measured from the semi-log plot of the time averaged $I_{\mathrm{e}}-V_{\mathrm{p}}$ curves (see Figure 4) is plotted as a function of $V_{\mathrm{p} 1}$ at $f=10 \mathrm{MHz}$, as shown in Figure 5. Both $V_{\text {dif }}$ and $V_{\mathrm{p} 1}$ are normalized by $T_{\mathrm{e}}$ which is also measured from the slope of the semi-log plot of the time averaged $I_{\mathrm{e}}-V_{\mathrm{p}}$ curves. Here, cross symbols are obtained from a DC plasma of $T_{\mathrm{e}}=0.4 \mathrm{eV}$, and $n_{\mathrm{e}}=1.1 \times 10^{9} \mathrm{~cm}^{-3} \quad\left(f_{\mathrm{pi}}=1.1 \mathrm{MHz}\right)$. Open circles are obtained from a DC plasma of $T_{\mathrm{e}}=1.0 \mathrm{eV}$, and $n_{\mathrm{e}}=5.3 \times 10^{9} \mathrm{~cm}^{-3} \quad\left(f_{\mathrm{pi}}=2.4 \mathrm{MHz}\right)$. Closed circles are obtained from a DC plasma of $T_{\mathrm{e}}=1.4 \mathrm{eV}$, and $n_{\mathrm{e}}=1.86 \times 10^{10} \mathrm{~cm}^{-3} \quad\left(f_{\mathrm{pi}}=4.5 \mathrm{MHz}\right)$. In all cases, the condition $f>f_{\mathrm{pi}}$ is satisfied. It is found that $V_{\mathrm{dif}}$ and $V_{\mathrm{p} 1}$ are well agreed with each other in a wide voltage range. Therefore, $V_{\mathrm{p} 1}$ can be measured precisely from $V_{\text {dif }}$.

\subsection{Time-Resolved Probe Characteristic Curves}

The experimental setup with a sampling convertor for obtaining a time-resolved probe 
characteristic curve is shown in Figure 1(a). An oscillating current flowing in a probe is inputted into the sampling converter. The characteristic curve at each time phase is drawn on the $X-Y$ recorder by changing the probe voltage $V_{\mathrm{p}}$ with fixing outputphase of the sampling comverter.

Probe characteristic curves at each time phase are shown in Figure 6, where $V_{\mathrm{p} 1}$ is 6.0 V. Plasma parameters are $T_{\mathrm{e}}=1.7 \mathrm{eV}, n_{\mathrm{e}}=8.2 \times 10^{9} \mathrm{~cm}^{-3}$, and $V_{\mathrm{s} 0}=7.9 \mathrm{~V}$, respectively.Curves in the case of $30 \mathrm{kHz}$ are shown by dotted lines. On the other hand, curves in the case of $10 \mathrm{MHz}\left(>f_{\mathrm{pi}}=3.0 \mathrm{MHz}\right)$ are shown by solid lines. Probe voltage is oscillating between $V_{\mathrm{p}}-V_{\mathrm{p} 1}$ and $V_{\mathrm{p}}+V_{\mathrm{p} 1}$. Instantaneous probe voltages at $\omega t=\pi / 2$ and $3 \pi / 2$ are $V_{\mathrm{p}}+V_{\mathrm{p} 1}$ and $V_{\mathrm{p}}-V_{\mathrm{p} 1}$, respectively, as shown in an inset in Figure 6 . $V_{\mathrm{f} 1}$ and $V_{\mathrm{f} 2}$ are floating potentials at $\omega t=\pi / 2$ and $3 \pi / 2$ in the case of $f=30 \mathrm{kHz}$. Potential difference $V_{\mathrm{f} 2}-V_{\mathrm{f} 1}$ is equal to $2 V_{\mathrm{p} 1}$ in Figure 6 .

There are four features in the probe current shown in Figure 6. First, the probe currents oscillate with the applied voltage in phase. This means that in this probe circuit only conduction current flows, but displacement current does not flow. Second, for $V_{\mathrm{p}}>V_{\mathrm{s} 0}+V_{\mathrm{p} 1}$, the amplitude of probe current at $10 \mathrm{MHz}$ is larger than that at 30 $\mathrm{kHz}$. This phenomenon will be discussed in section 5 . Third, at $\omega t=0, \pi$ and $2 \pi$, oscillating potential difference between the probe and plasma becomes $0 \mathrm{~V}$, so that two characteristic curves shown by a dotted line and a solid line overlap each other. These curves also agree with a curve in the case of $V_{\mathrm{p} 1}=0 \mathrm{~V}$. In other words, one can obtain exact plasma parameters mentioned above by using the curves at $\omega t=0, \pi$ and $2 \pi$ without any effect from RF electric field. It is also indicated that the time-averaged characteristics curve shown by dotted lines has two inflection points as shown in

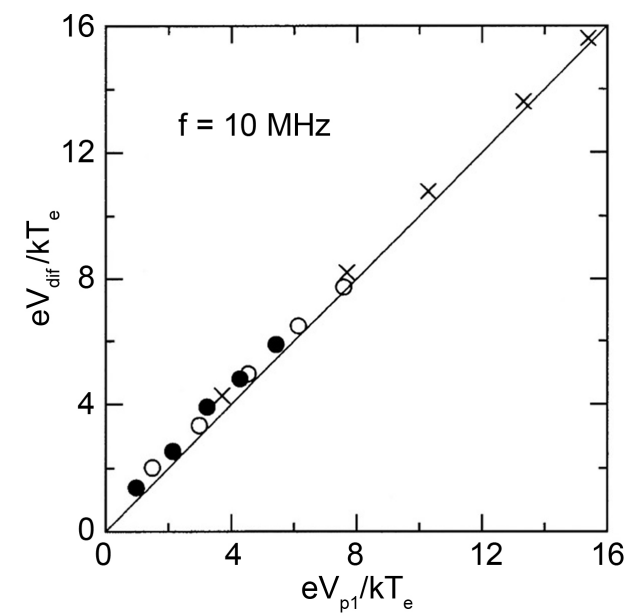

Figure 5. Variation of normalized potential difference $V_{\text {dif }} / k T_{\text {e }}$ between upper and lower inflection points on a semi-log plot of the timeaveraged probe characteristic curve as a function of normalized amplitude $V_{\mathrm{p} 1} / k T_{\mathrm{e}}$ applied to the probe. Three symbols are explained in the text. $f=10 \mathrm{MHz}$ and $P_{\mathrm{Ar}}=0.133 \mathrm{~Pa}$. 


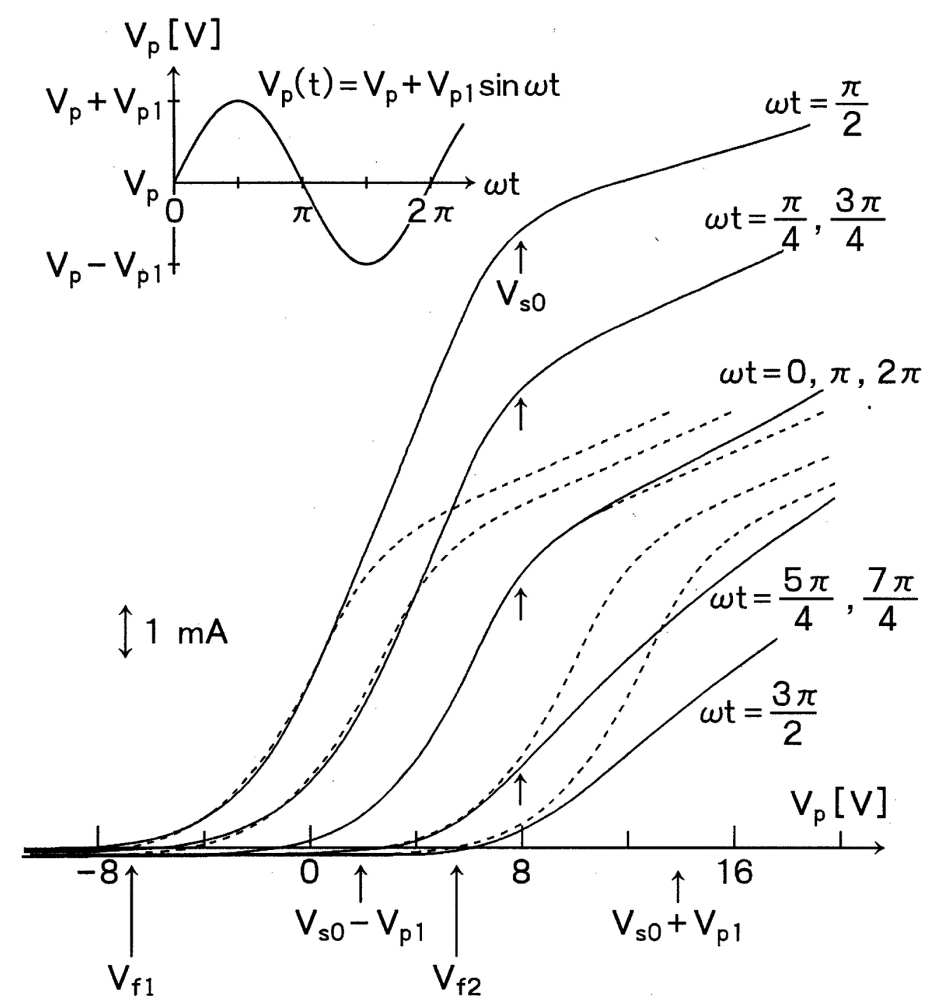

Figure 6. Time-resolved probe characteristic curves at each time phase for $30 \mathrm{kHz}$ (dotted lines) and $10 \mathrm{MHz}$ (solid lines). Inset schematically shows the time phase of applied voltage to the probe. Here, voltage amplitude $V_{\mathrm{p} 1}$ is $6.0 \mathrm{~V}$, and $f_{\mathrm{pi}}=3.1 \mathrm{MHz}$.

Figure 2(a). Fourth, in the retarding range $V_{\mathrm{p}}<V_{\mathrm{s} 0}-V_{\mathrm{p} 1}$, the probe currents in the cases of $30 \mathrm{kHz}$ and $10 \mathrm{MHz}$ are overrapped each other, indicating that electron temperature $T_{\mathrm{e}}=1.7 \mathrm{eV}$ can be provided from the time-averaged probe characteristic curves shown by solid lines in the retarding potential range. This phenomenon will be also discussed in Secsion 5.

Each curve shown by solid line has an inflection point at $V_{\mathrm{p}}=V_{\mathrm{s} 0}$, so that the time-averaged characteristic curves shown by solid line has at least one inflection point at $V_{\mathrm{p}}=V_{\mathrm{s} 0}$ [see Figure 2(c)]. RF probe current has the maximum at $V_{\mathrm{p}}=V_{\mathrm{s} 0}=7.9 \mathrm{~V}$ as shown in Ref. [21].

\section{Experiments Using RF Discharge Plasma}

\subsection{Experimental Device for Drawing Plasma Characteristics}

The experimental device and circuit for obtaining a probe characteristic in RF plasmas with space potential oscillation by using a DC-biased probe is shown in Figure 1(b), where the cylindrical chamber is grounded. RF discharge at $8.2 \mathrm{MHz}$ is carried out. The experiment is performed in a cylindrical chamber of $23 \mathrm{~cm}$ in diameter and $50 \mathrm{~cm}$ in length with an cylindrical electrode ( $22 \mathrm{~cm}$ in diameter) to which RF power of $200 \mathrm{~W}$ is applied via matching unit. Argon is used as a working gas at pressure of $0.133 \mathrm{~Pa}$. 
Background pressure is $10^{-3} \mathrm{~Pa}$. A tantalum probe same as what is used in Figure 1(a) is placed in the center of the device. It was movable in the axial direction. The output voltage of plasma generator, which is suppressed to a one-tenth by an attenuator, is inputted to a trigger terminal of the sampling convertor.

\subsection{Time-Resolved Probe Characteristic Curves in RF Discharge Plasmas}

Time-resolved probe characteristic curves are shown by solid lines in Figure 7, where a time-averaged probe curve $\left\langle I_{\mathrm{p}}(t)\right\rangle_{t}$ is shown by a dotted line. Instantaneous voltage of space potential at $\omega t=\pi / 2$ and $3 \pi / 2$ are $V_{\mathrm{s} 0}+V_{\mathrm{s} 1}$ and $V_{\mathrm{s} 0}-V_{\mathrm{s} 1}$, respectively, as shown by an inset in Figure 7. Here, $V_{s 1}$ is the amplitude of RF space potential. RF potential difference between the probe and plasma vanishes at $\omega t=0, \pi$ and $2 \pi$, so that $T_{\mathrm{e}}, n_{\mathrm{e}}$, and $V_{\mathrm{s} 0}$ can be obtained from the characteristic curves at these time phases as mentioned in Figure 6. $T_{\mathrm{e}}=7.4 \mathrm{eV}, n_{\mathrm{e}}=1.0 \times 10^{9} \mathrm{~cm}^{-3}$, and $V_{\mathrm{s} 0}=48.5 \mathrm{~V}$ are obtained. The time-averaged probe curve shown by dotted line has only one inflection point at $V_{\mathrm{p}}=V_{\mathrm{s} 0}$ as also shown in Figure 2(c). Time-resolved curves shown by solid lines have also inflection point at $V_{\mathrm{p}}=V_{\mathrm{s} 0}$. The oscillating probe current for $V_{\mathrm{p}}>V_{\mathrm{s} 0}+V_{\mathrm{s} 1}$ has a large amplitude, similar to the results in Figure 6. This phenomenon will be also discussed in Section 5.

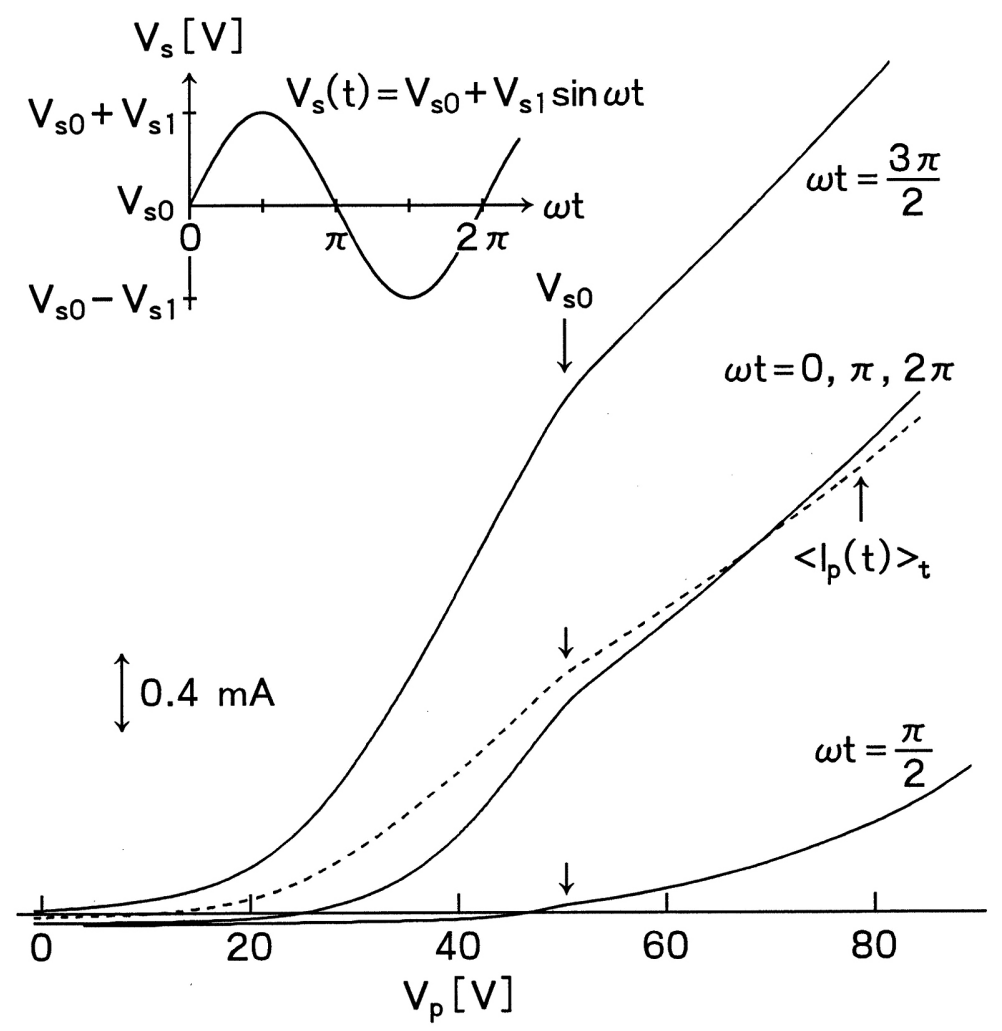

Figure 7. Probe characteristic curves in RF discharge plasma at each time phase. Inset schematically shows the time phase of space potential. Ion plasma frequency is $f_{\mathrm{pi}}=1.0 \mathrm{MHz}$ and RF frequency is $f=8.2 \mathrm{MHz}$. 


\subsection{Semi-Log Plots of Time-Resolved Probe Electron Current $I_{\mathrm{e}}$}

Figure 8 shows semi-log plots of time-resolved electron current $I_{\mathrm{e}}$ of the probe at four time phases; i.e., $\omega t=3 \pi / 4, \pi, 5 \pi / 4$ and $3 \pi / 2$. The experimental condition is the same as that in Figure 7. Because an RF electric field does not exist at $\omega t=\pi$, the time-resolved curve has only one inflection point at $V_{\mathrm{p}}=V_{\mathrm{s} 0}$. Plasma parameters mentioned above can be provided from this curve. Because all four straight lines fitting to the semi-log plots in the retarding potential range are parallel, it is confirmed that $T_{e}$ of this RF discharge plasma is constant, being independent of the time phase.Since frequency $f$ of RF potential fluctuation is much lower than electron plasma frequency $f_{\mathrm{pe}}$, i.e., $f \ll f_{\mathrm{pe}}(\simeq 1 \mathrm{GHz})$, electrons can easily follow the change of space potential fluctuation and can be isothermalized to a single Maxwellian.

\subsection{Semi-Log Plots of Time-Averaged Probe Electron Current $I_{e}$}

Semi-log plots of the time-averaged electron current $\left\langle I_{\mathrm{e}}(t)\right\rangle_{t}$ and time-resolved electron current $I_{\mathrm{e}}$ at $\omega t=\pi$ are shown in Figure 9. Because an RF electric field does not exist in the case of $\omega t=\pi$, this curve has only one inflection point. Plasma parameters can be provided from this curve, namely $T_{e}=7.4 \mathrm{eV}, n_{\mathrm{e}}=1.0 \times 10^{9} \mathrm{~cm}^{-3}$, and $V_{\mathrm{s} 0}=48.5 \mathrm{~V}$. In the case of time-averaged curve, the potential difference $22.0 \mathrm{~V}$ between upper and lower inflection points can be thought to give the amplitude $V_{\mathrm{s} 1}$ of RF space potential oscillation, as shown in Figure 4 . The validity of $V_{s 1}$ is verified by an emissive probe method described in the following Section 4 . The other plasma parameters $T_{\mathrm{e}}, n_{\mathrm{e}}$, and $V_{\mathrm{s} 0}$, which are derived from the time-resolved curve at $\omega t=\pi$, can be also obtained from the semi-log plot of the time-averaged characteristic curve.

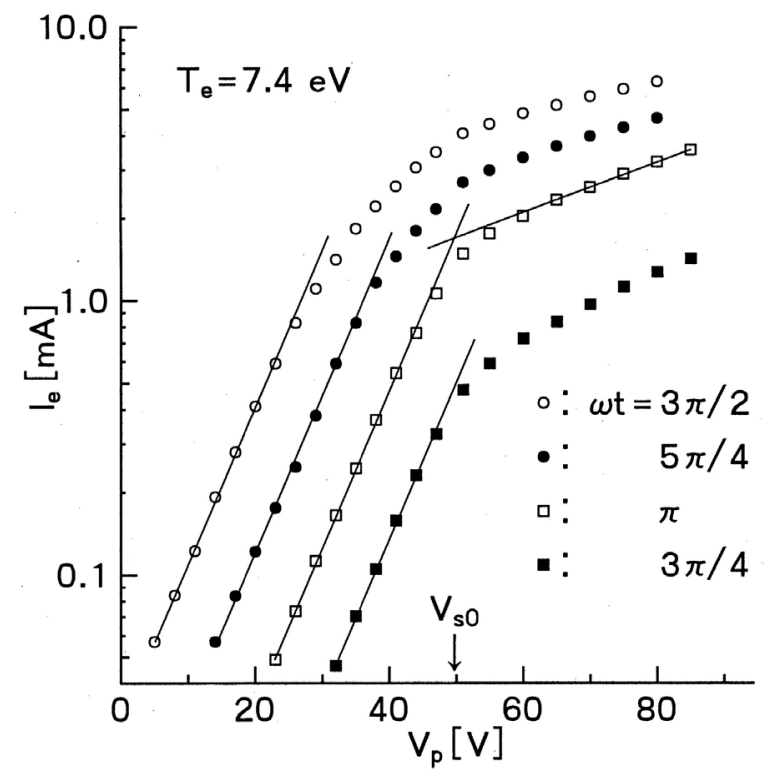

Figure 8. Semi-log plots of time-resolved $I_{\mathrm{e}}-V_{\mathrm{p}}$ characteristic curves at each time phase in RF plasma. $f_{\mathrm{pi}}=1.0 \mathrm{MHz}$ and $f=8.2 \mathrm{MHz}$. 


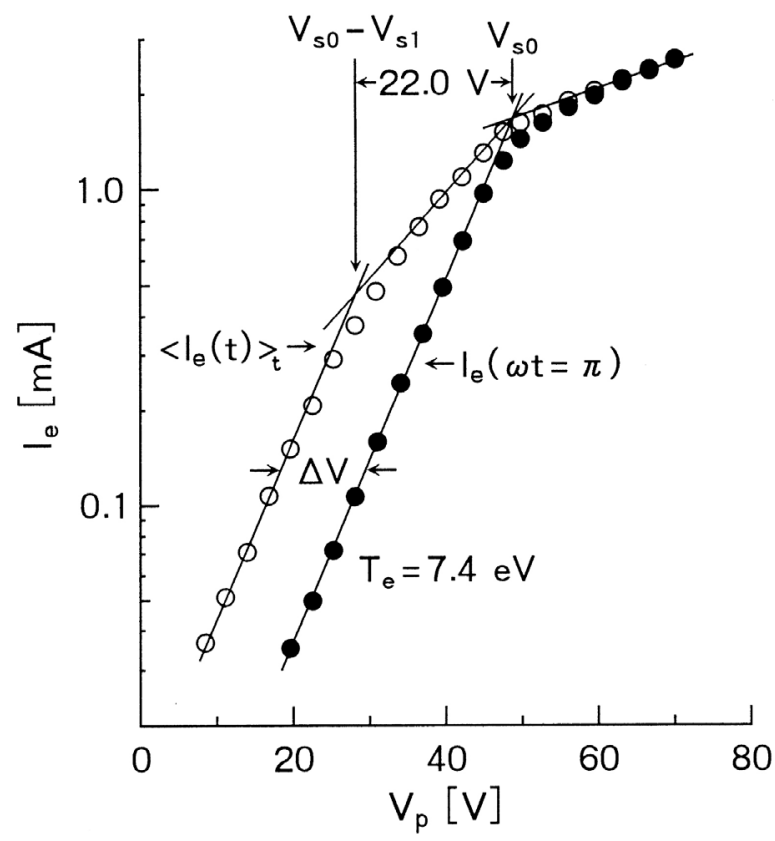

Figure 9. Semi-log plots of electron currents $\left\langle I_{\mathrm{e}}(t)\right\rangle_{t}$ (open circles) and $I_{\mathrm{e}}(\omega t=\pi)$ (closed circles). $\left\langle I_{\mathrm{e}}(t)\right\rangle_{t}$ is the time-averaged electron current. $I_{\mathrm{e}}(\omega t=\pi)$ is electron current at $\omega t=\pi . f_{\mathrm{pi}}=1.0 \mathrm{MHz}$ and $f=8.2 \mathrm{MHz}$.

From this figure, it can be also measureed that $\Delta V$ defined by Equation (4) is 11.74 V. By substituting $\Delta V=11.74 \mathrm{~V}$ and $T_{\mathrm{e}}=7.4 \mathrm{eV}$ into Equation (4), $V_{\mathrm{p} 1}=22.2 \mathrm{~V}$ is obtained. This value is almost equal to $V_{\mathrm{s} 1}=22.0 \mathrm{~V}$. Therefore, it is confirmed that Equation (5) can be also applied to RF plasmas. It should be noted that the inflection point method presented here is quite easy to obtain $V_{\mathrm{s} 1}$ than a method using Equation (4).

From the technique described above, plasma parameters of RF plasmas can be easily obtained by using almost the same probe circuit as used for DC discharge plasmas, by combining a Microsoft Visual C++ software and a personal computer controlled Source Meter-2400 manufactured by Keithley Instruments. This technique is very convenient and useful for the measurement of plasma parameters of RF plasmas efficiently.

\section{Comparison with Other Measurement Methods}

As shown in Section 3, plasma parameters of RF discharge plasma were measured easily by a semi-log plot of the time-averaged characteristic curve of Langmuir probe. In order to ensure the reliability of the data provided by the probe method above, it is necessary to compare the plasma parameters with those provided using measurement procedures based on different principles. The comparison experiments were carried out for existence of inflection point at $V_{\mathrm{s} 0}+V_{\mathrm{s} 1}$, validity of electron temperature $T_{\mathrm{e}}$, and the mechanism of electron current enhancement and suppression at $\omega t=3 \pi / 2$ and 
$\pi / 2$, respectively, in RF plasmas (see Figure 7).

\subsection{Inflection Point Measurement with Emission Probe Method}

Emission probes were employed to measure the space potential of DC discharge plasma exactly [22] [23]. A few researchers reported the methods for measuring the amplitude of plasma space potential by using the inflection point technique [24]-[26]. Here, emission probe method is employed to confirm the existence of the inflection points at $V_{\mathrm{s} 0} \pm V_{\mathrm{s} 1}$ in RF plasmas and to verify the presence of lower inflection point at $V_{\mathrm{s} 0}-V_{\mathrm{s} 1}$ on the semi-log plot of time-averaged probe characteristic curve in RF plasmas.

The experiment was performed in the RF discharge tube shown in Figure 1(b). $P_{\mathrm{Ar}}$, $T_{\mathrm{e}}$, and $n_{\mathrm{e}}$ are $0.67 \mathrm{~Pa}, 6.6 \mathrm{eV}, 1.5 \times 10^{9} \mathrm{~cm}^{-3}$, respectively. A conventional emission probe made of tantalum hair pin wire of $0.125 \mathrm{~mm}$ in diameter is employed in order to measure the amplitude of the RF fluctuation of space potential. The emission probe is covered with an alumina tube with outer diameter of $2 \mathrm{~mm}$ with two holes, except for the probe tip [22]. The filament heating current is maintained by a lead storage battery to prevent $50 \mathrm{~Hz}$ signal from spreading over the probe and discharge circuit.

Time-averaged characteristic curves of the emission probe are shown in Figure 10. In the case of probe heating current $I_{\mathrm{h}}=0 \mathrm{~A}$, the curve similar to that plotted by dotted curve in Figure 7 is obtained. Therefore, the inflection point appears at one point $V_{\mathrm{s} 0}$. Although the semi-log plot of this curve is not shown in this figure, time-averaged space potential $V_{\mathrm{s} 0}=45.0 \mathrm{~V}$ and amplitude of space potential $V_{\mathrm{s} 1}=19.8 \mathrm{~V}$ are ob-

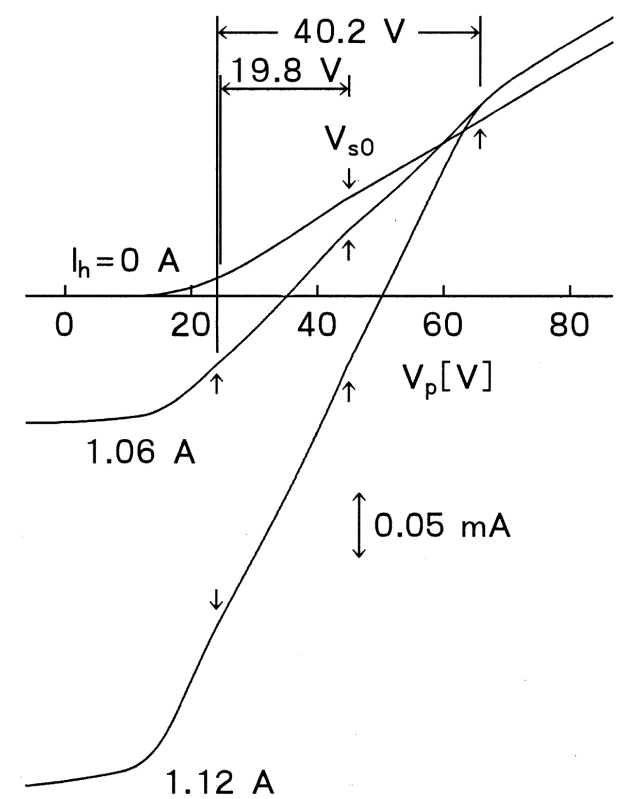

Figure 10. Time-averaged emissive probe $I_{\mathrm{e}}-V_{\mathrm{p}}$ curve with heating current $I_{\mathrm{h}}$ as a parameter. Allows show inflection points of the curves. $V_{\mathrm{s} 0}$ is time-averaged space potential of the RF plasma. $f_{\mathrm{pi}}=1.56 \mathrm{MHz}$ and $f=8.2 \mathrm{MHz}$. 
tained from the semi-log plot of the time-averaged electron current. However, in the cases of $I_{\mathrm{h}}=1.06$ and $1.12 \mathrm{~A}$ there appear three inflection points in both curves as pointed by arrows. The voltage of the middle point is the same as that in the case of $I_{\mathrm{h}}=0 \mathrm{~A}$. The potential difference between upper and lower points is $40.2 \mathrm{~V}$ as shown in Figure 10 and it is almost equal to $39.6 \mathrm{~V}$ which is twice of the amplitude of the space potential $19.8 \mathrm{~V}$. Therefore, it is confirmed experimentally that $V_{\mathrm{s} 0}$ and $V_{\mathrm{s} 1}$ obtained from the emission probe method well agree with the values provided by the Langmuir probe method shown in Figures 7-9.

\subsection{Electron Temperature Measurement with Ion Acoustic Wave Method}

Ion acoustic wave method is one of the useful ways for obtaining an electron temperature in RF discharge plasmas [27]-[30]. The plasma generation and the measurement system for ion acoustic wave are shown schematically in Figure 11. They are housed in a stainless steel vacuum chamber with an inner diameter of $60 \mathrm{~cm}$ and a length of 100 $\mathrm{cm}$. This reactor, $7 \mathrm{~cm}$ in diameter and $12 \mathrm{~cm}$ in length, is the same as that shown in Figure 1 of Ref. [31] except that plasma is produced by an RF discharge. A cylindrical

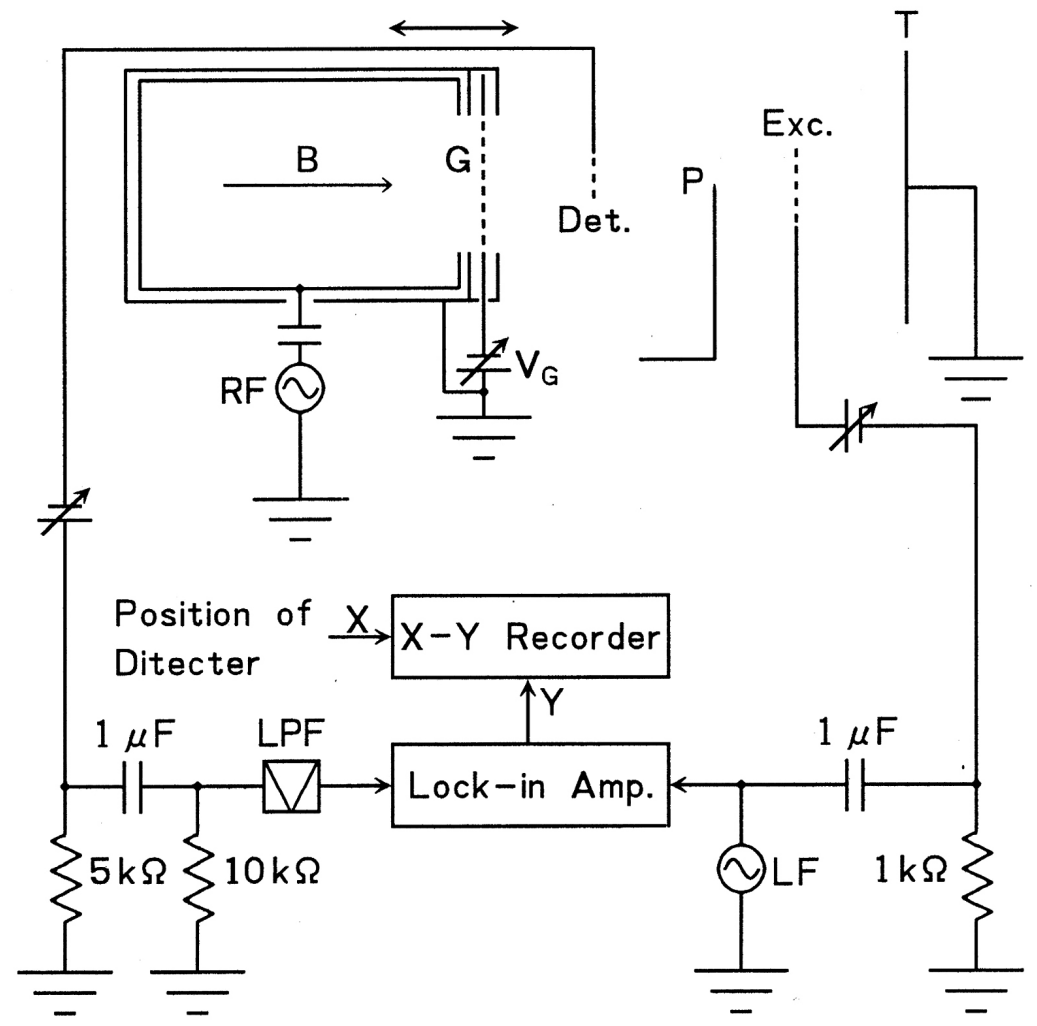

Figure 11. Experimental apparatus for a measurement of ion acoustic wave pattern with an exciter (Exc.) and a detector (Det.). $\mathrm{P}$ is a probe for $T_{\mathrm{e}}$ measurement. $V_{\mathrm{G}}$ is DC grid voltage for controlling the plasma flow. RF and LF provide RF discharge frequency $f=25 \mathrm{MHz}$ and wave excitation frequency $f_{\text {ex }}$, respectively. 
Langmuir probe $\mathrm{P}$ (diameter $0.6 \mathrm{~mm}$, length $1.8 \mathrm{~mm}$ made of tantalum wire) is spotwelded to a copper core wire of a $50 \Omega$ semi-rigid coaxial-cable (outer diameter 2.2 $\mathrm{mm}$ ), which is sleeved with a glass tube. The gas pressure is evacuated to a pressure of $10^{-3} \mathrm{~Pa}$ by using a diffusion pump and a rotary pump. Argon plasma is generated by RF (25 MHz) discharge.

A grid electrode $\mathrm{G}$ located at the outlet of the RF electrode is used for controlling the electron temperature in the downstream region of plasma [32]-[35]. The grid G (16 $\mathrm{mesh} / \mathrm{in}$.) is made of 0.29 - $\mathrm{mm}$-diameter stainless steel wire and installed on a $4.2-\mathrm{cm}$ diameter aluminum ring flame which is connected to the earth using capacitors which exhibit low impedance to RF while allowing DC biasing of this electrode [32]. These capacitors are not shown in Figure 11.

Ion acoustic waves are excited by an exciter (Exc.: 20 mesh/in., 2-cm diameter) and detected by a movable detector (Det.: $8 \mathrm{mesh} / \mathrm{in}$., $1.5-\mathrm{cm}$ diameter). Exc. and Det. are made of a grid of the stainless steel wire of $0.29 \mathrm{~mm}$ in diameter. The frequency of ion acoustic wave is changed by a low frequency (LF) oscillator between $50 \mathrm{kHz}$ and 300 $\mathrm{kHz}$. Argon pressure is $0.67 \mathrm{~Pa}$. A magnetic field of $20 \times 10^{-4} \mathrm{~T}$ is applied in order that axial electron density distribution becomes uniform and the ions suffer one-dimensional compressions in the plane waves [36] [37]. A wave pattern is drawn on the $X-Y$ recorder through a lock-in amplifier.

The dispersion relation given by Equation (6) for ion acoustic waves is derived from a fluid theory under the conditions $\left(\lambda / \lambda_{\mathrm{De}}\right)^{2} \gg 1$ and $T_{\mathrm{e}} / T_{\mathrm{i}} \gtrsim 2$.

$$
f_{\mathrm{ex}} \lambda=C_{\mathrm{s}}=\left\{\left(T_{\mathrm{e}}+3 T_{\mathrm{i}}\right) / M_{\mathrm{i}}\right\}^{1 / 2}
$$

Here, $f_{\mathrm{ex}}, \lambda$ and $C_{\mathrm{s}}$ are frequency, wave length, and velocity of the ion acoustic wave, respectively [38]. Using argon gas, in the case of $T_{\mathrm{e}} / T_{\mathrm{i}} \gg 1$, this expression is referred to Equation (7)

$$
f_{\mathrm{ex}} \lambda=156 \sqrt{T_{\mathrm{e}}}
$$

Here, the units of $\lambda, T_{\mathrm{e}}$, and $f_{\mathrm{ex}}$ are $\mathrm{cm}, \mathrm{eV}$, and $\mathrm{kHz}$, respectively. Therefore, electron temperature $T_{\mathrm{e}}$ can be derived by measuring the wave length $\lambda$ of the ion acoustic at the frequency $f_{\mathrm{ex}}$.

Wave patterns at $f_{\mathrm{ex}}=100 \mathrm{kHz}$ for $V_{\mathrm{G}}=0 \mathrm{~V}$ and $-40 \mathrm{~V}$ are shown in Figure 12. The wavelength of the ion wave becomes short with a drop of $V_{G}$. The wavelengths at $V_{\mathrm{G}}=0 \mathrm{~V}$ and $-40 \mathrm{~V}$ are $2.0 \mathrm{~cm}$ and $1.25 \mathrm{~cm}$, respectively. From this result, the electron temperature at $V_{\mathrm{G}}=0 \mathrm{~V}$ is calculated to be $1.64 \mathrm{eV}$ by substituting $f_{\mathrm{ex}}=100 \mathrm{kHz}$ and $\lambda=2.0 \mathrm{~cm}$ in Equation (7). The relations between $f_{\mathrm{ex}}$ and $1 / \lambda$ in the cases of grid voltage $V_{\mathrm{G}}=40 \mathrm{~V}, 0 \mathrm{~V}$, and $-40 \mathrm{~V}$ are shown in Figure 13. The slope of the straight line corresponding to the phase velocity of the ion acoustic wave becomes small with a drop of $V_{\mathrm{G}}$. This result indicates that electron temperature drops as $V_{\mathrm{G}}$ decreases.

Electron temperatures calculated by the ion acoustic method with Equation (7) and measured by the probe method are shown in Figure 14 as a function of $V_{\mathrm{G}}$ by closed and open circles, respectively. Both electron temperatures are well agreed with each 

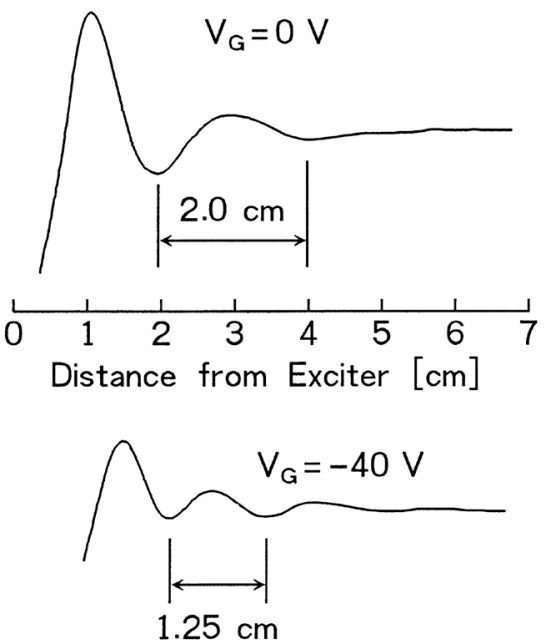

Figure 12. Typical wave patterns at $f_{\mathrm{ex}}=100 \mathrm{kHz}$, measured by lock-in amplifier with DC grid voltage $V_{\mathrm{G}}$ as a parameter. Ion plasma frequency is $f_{\mathrm{pi}}=1.7 \mathrm{MHz}$ and RF discharge frequency is $25 \mathrm{MHz}$.

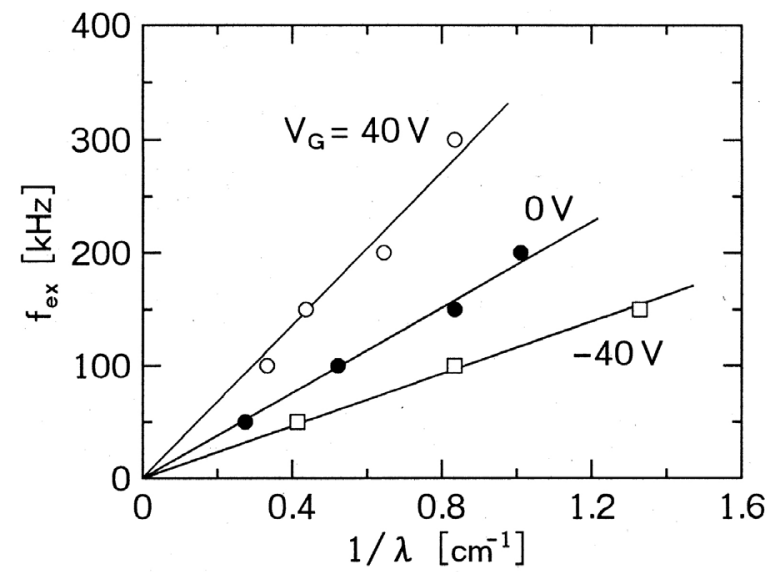

Figure 13. Relations between $f_{\mathrm{ex}}$ and inverse of ion acoustic wavelength $1 / \lambda$ with $\mathrm{DC}$ grid voltage $V_{\mathrm{G}}$ of 40 $\mathrm{V}, 0 \mathrm{~V}$, and $-20 \mathrm{~V}$. $f_{\mathrm{pi}}=1.7 \mathrm{MHz}$ and $f=25 \mathrm{MHz}$.

other. $T_{\mathrm{e}}$ decreases from $4.2 \mathrm{eV}$ to about $0.5 \mathrm{eV}$ by a decrease in $V_{\mathrm{G}}$. Since the electron temperatures obtained by two methods well fit each other, it is confirmed that electron temperature provided by the probe method is correct.

\subsection{Electron Current Variations Using a Square Pulse in DC Discharge Plasmas}

Since it was confirmed that probe current response on RF voltage superimposed to DC biased probe in DC plasmas was equivalent to that on DC biased probe in RF plasmas (see Figure 6 and Figure 7), a mechanism on the current enhancement and suppression for $V_{\mathrm{p}}(t)>V_{\mathrm{s} 0}+V_{\mathrm{s} 1}$ at $\omega t=3 \pi / 2$ and $\pi / 2$, respectively, in RF plasmas (see 


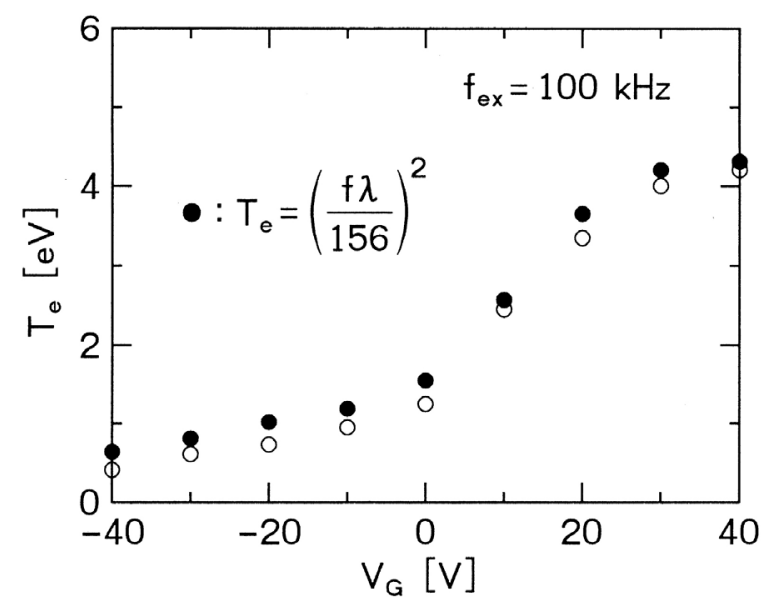

Figure 14. Electron temperatures $T_{\mathrm{e}}$ calculated from Equation (7) (closed circles) and measured by a probe method (open circles) in RF plasmas, as a function of the DC grid voltage $V_{\mathrm{G}} \cdot f_{\mathrm{pi}}=1.7 \mathrm{MHz}$ and $f=25 \mathrm{MHz}$.

Figure 7) was investigated by using a square pulse voltage superimposed to DC probe voltage in DC plasma in an experimental apparatus shown in Figure 1(a). Rise time, time width, and amplitude of the square pulse voltage $V_{\text {pu }}$ are $0.05 \mu \mathrm{s}, 10 \mu \mathrm{s}$, and $\pm 5 \mathrm{~V}$, respectively. The rise time $0.05 \mu$ s is equivalent to a quarter period of $5 \mathrm{MHz}$ signal. This pulse voltage is applied to the DC biased probe voltage $V_{\mathrm{dc}}$. Therefore, the voltage of the disc probe changes from $V_{\mathrm{dc}}-5 \mathrm{~V}$ to $V_{\mathrm{dc}}+5 \mathrm{~V}$ [19].

When $V_{\mathrm{pu}}=0 \mathrm{~V}$, the characteristic $I_{\mathrm{p}}-V_{\mathrm{p}}$ curve of the disc probe is shown in Figure 15(a) under the condition that $P_{\mathrm{Ar}}$ and $B$ are $0.133 \mathrm{~Pa}$ and $50 \times 10^{-4} \mathrm{~T}$, respectively. The disc probe is put at the position of a radius of $3 \mathrm{~cm}$ so that high energy electrons cannot arrive at this place. Plasma parameters are obtained, i.e. $T_{\mathrm{e}}=0.64 \mathrm{eV}$, $n_{\mathrm{e}}=7.8 \times 10^{9} \mathrm{~cm}^{-3}$, and $V_{\mathrm{s} 0}=4.6 \mathrm{~V}$, thus $f_{\mathrm{pi}}=2.6 \mathrm{MHz}$. Figure $15(\mathrm{~b})$ shows temporal variations of probe current $I_{\mathrm{p}}$ with initial probe voltage $V_{\mathrm{dc}}$ as a parameter. In the case of $V_{\mathrm{dc}}=-1.6 \mathrm{~V}$, the pulsed voltage changes from $V_{\mathrm{dc}}-5 \mathrm{~V}=-6.6 \mathrm{~V}$ to $V_{\mathrm{dc}}+5 \mathrm{~V}=3.4 \mathrm{~V} \quad\left(<V_{\mathrm{s} 0}\right)$. In this case, electron current attained immediately to the stationary current without any deformation (see bottom trace). On the other hand, when $V_{\mathrm{dc}}+5 \mathrm{~V}>V_{\mathrm{s} 0}$, i.e. $V_{\mathrm{dc}}>-0.4 \mathrm{~V}$, the electron current quickly overshoots in the initial response, and such overshooting of the electron current attains the maximum as $V_{\mathrm{dc}}$ approaches to $V_{\mathrm{s} 0}$. Further, in this case, after overshooting the electron current diminishes and returns to a minimum value, evolving an amplitude oscillation decaying in time. A period of this oscillation is about $1.71 \mu \mathrm{s}$, corresponding to the frequency 0.58 $\mathrm{MHz}$ which is lower than $f_{\mathrm{pi}}=2.6 \mathrm{MHz}$. From this pulse experiment, it was known that the electron current increases at $\omega t=\pi / 2$ in Figure 6 and at $\omega t=3 \pi / 2$ in Figure 7 is quite similar to the current response at the initial stage when the positive square voltage was applied to the probe.

During the initial time response, time-resolved probe measurements are carried out in a DC plasma for measuring the space potential profile in front of the probe. Here, 


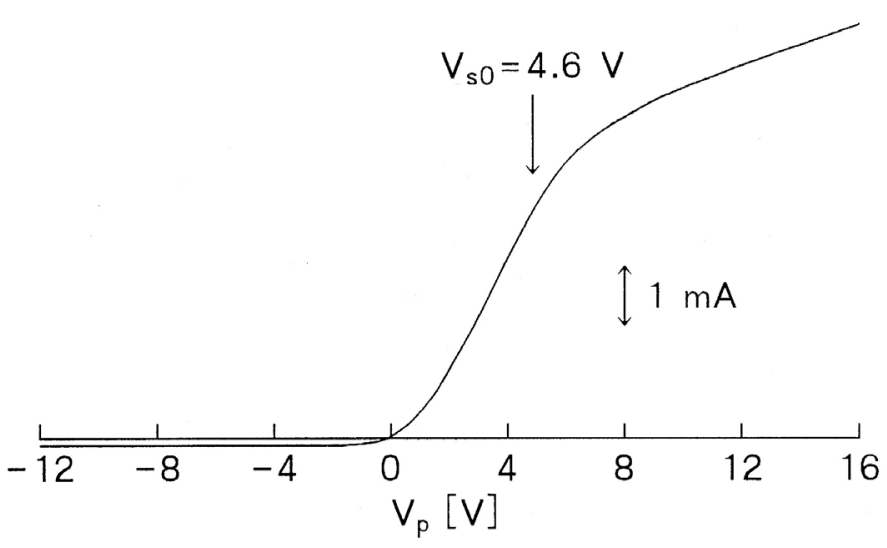

(a)

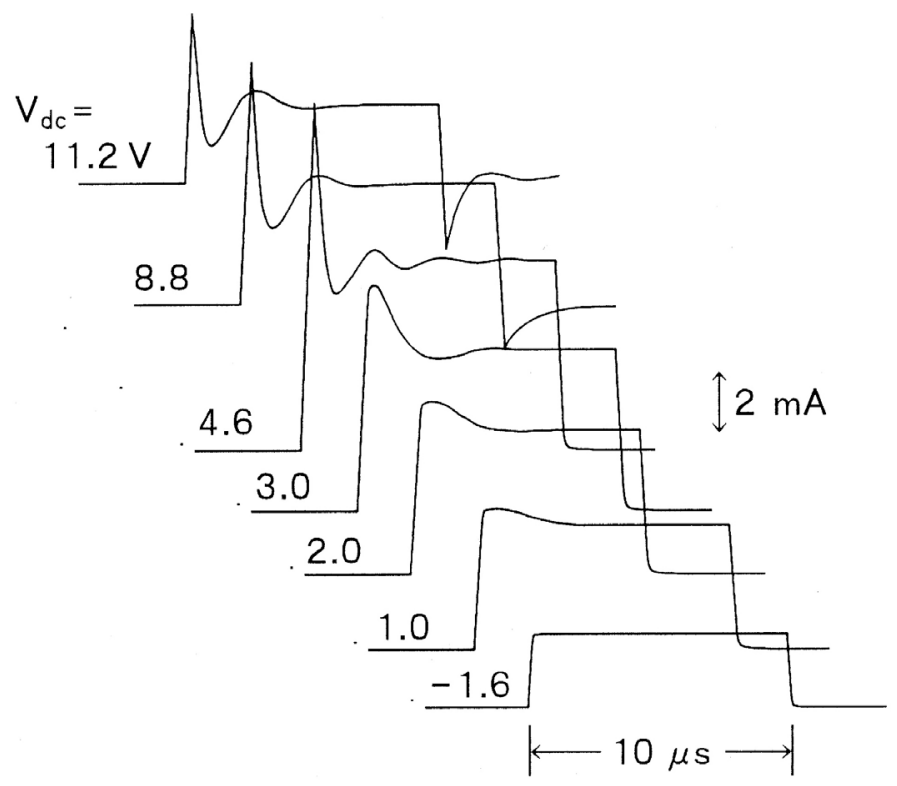

(b)

Figure 15. (a) Characteristic curve of a disc probe at pulse height of $V_{\mathrm{pu}}=0 \mathrm{~V}$. (b) Temporal variation of electron current of the disc probe with $V_{\mathrm{dc}}$ as a parameter. $f_{\mathrm{pi}}=2.6 \mathrm{MHz}$.

$T_{\mathrm{e}}=1.16 \mathrm{eV}, \quad n_{\mathrm{e}}=8.3 \times 10^{9} \mathrm{~cm}^{-3}, \quad V_{\mathrm{s} 0}=3.8 \mathrm{~V}, \quad$ and $f_{\mathrm{pi}}=2.7 \mathrm{MHz}$ under $P_{\mathrm{Ar}}=0.133 \mathrm{~Pa}$ and $B=35 \times 10^{-4} \mathrm{~T}$. Figure $16(\mathrm{a})$ and Figure $16(\mathrm{~b})$ show axial $(z)$ distribution of (a) space potential $V_{\mathrm{s}}$ and (b) electron current ratio $J_{\text {es }} / J_{\text {es }}(\bullet)$ near the disc probe, respectively. Space potentials are obtained by using time-resolved $I_{\mathrm{p}}-V_{\mathrm{p}}$ characteristic curves of the cylindrical probe. The voltage of the disc probe changes from $5 \mathrm{~V}$ to $15 \mathrm{~V}$ in $0.05 \mu \mathrm{s}$. The symbols $\circ, \Delta$ and $\bullet$ correspond to the times when the current becomes the maximum, minimum and steady state values, respectively, as shown by an inlet in Figure 16(a). In the case of the steady state $(\bullet)$, the space potential profile is uniform, even close to the probe position at $z=0$. Here, Debye length obtained from $T_{\mathrm{e}}=1.16 \mathrm{eV}$ and $n_{\mathrm{e}}=8.3 \times 10^{9} \mathrm{~cm}^{-3}$ is $\lambda_{\mathrm{D}} \simeq 0.1 \mathrm{~mm}$. 

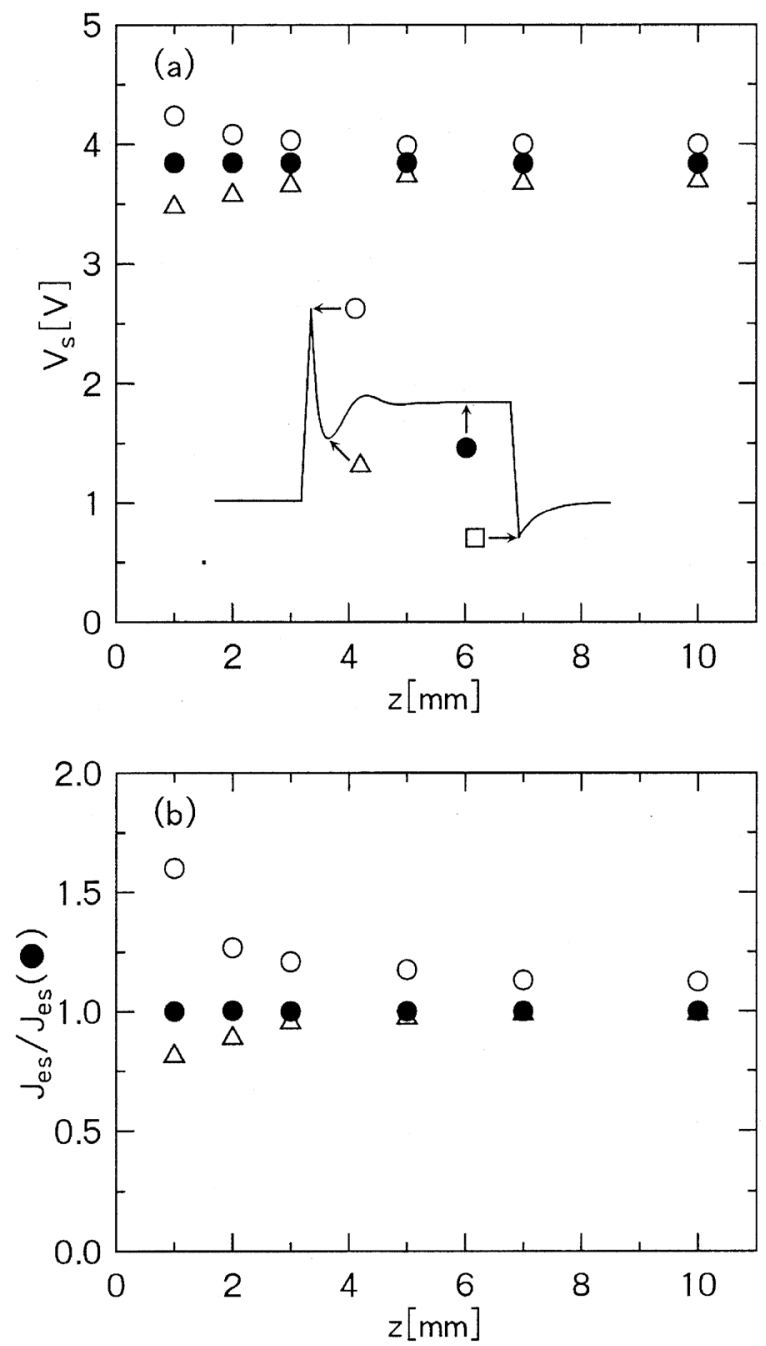

Figure 16. Axial $z$ distributions of (a) space potential $V_{\mathrm{s}}$ and (b) saturation current ratio $j_{\mathrm{es}} / j_{\mathrm{es}}(\bullet)$ at the times indicated by the symbols $\circ, \Delta$ and $\bullet$ shown in an inlet, corresponding to the current maximum, minimum and steady state values, respectively. The symbol $\square$ indicates the current minimum at the end of the square pulse.

On the other hand, in the case of the current maximum time ( 0 ) the space potential simply decreases in the $z$ direction from $15 \mathrm{~V}$ to $4 \mathrm{~V}$ within a range of $5 \mathrm{~mm}$ from $z=0$ $\mathrm{mm}$. In other words, the positive probe potential leaks further into the bulk plasma up to $z=5 \mathrm{~mm}$, which is far from the sheath edge $\left(z \simeq 5 \lambda_{\mathrm{D}}\right)$ of the probe. Therefore, the probe would collect more electrons from the bulk plasma [39]. Therefore, probe current becomes larger than that in the steady state, as shown by opened circles in Figure 16(b). On the other hand, at the current minimum time $(\Delta)$ the space potential becomes lower than that in the steady state as shown in Figure 16(a), indicating that there appears a potential minimum dip between $z=0 \mathrm{~mm}$ to $1 \mathrm{~mm}$. Because of the formation of this potential dip the probe electron current is much suppressed com- 
pared to that in the steady state value, as also shown in Figure 16(b) [40] [41].

At the time pointed by square ( $\square$ ) in Figure 16(a), one can also confirm an appearance of the potential dip in front of the disc probe, resulting in a suppression of electron current, although these data are not shown in Figure 16. This result is closely related to the current suppression at $\omega t=3 \pi / 2$ in Figure 6 and at $\omega t=\pi / 2$ in Figure 7 .

\section{Discussion}

In our experiments using a DC plasma, two phenomena were observed. First, when $V_{\mathrm{p}}$ is higher than $V_{\mathrm{s} 0}+V_{\mathrm{p} 1}$, the amplitude of the oscillating probe current for $10 \mathrm{MHz}$ was larger than that for $30 \mathrm{kHz}$, as shown in Figure 7. Second, instantaneous probe current does not depend on the frequency when $V_{\mathrm{p}}$ is lower than $V_{\mathrm{s} 0}-V_{\mathrm{p} 1}$, where electrons in the ion sheath receive a retarding force during the complete cycle. Let us here discuss why these two phenomena occur. It is convenient for the explanations to divide the range of probe voltage $V_{\mathrm{p}}$ into two regions, i.e., $V_{\mathrm{p}}<V_{\mathrm{s} 0}-V_{\mathrm{p} 1}$ and $V_{\mathrm{p}}>V_{\mathrm{s} 0}+V_{\mathrm{p} 1}$.

\subsection{Assumption}

In order to explain the two phenomena mentioned above it is necessary to make the following simplified assumptions.

1) Electrons do not collide with particles of neutral gas inside the probe sheath. This requirement is reduced to

$$
\lambda_{\mathrm{D}} / \lambda_{\mathrm{c}}=2.4 \times 10^{19} \sigma P_{\mathrm{Ar}} \sqrt{T_{\mathrm{e}}(\mathrm{eV}) / n_{\mathrm{e}}\left(\mathrm{cm}^{-3}\right)} \ll 1, .
$$

where $\sigma$ is the collision cross section in $\mathrm{cm}^{2}$ [4]. When $T_{\mathrm{e}}=1.16 \mathrm{eV}$ and $n_{\mathrm{e}}=8.3 \times 10^{9} \mathrm{~cm}^{-3}$, Debye length becomes $\lambda_{\mathrm{D}} \simeq 0.1 \mathrm{~mm}$. On the other hand, electron collision mean-free path becomes $\lambda_{\mathrm{c}} \simeq 1 \mathrm{~mm}$ at $P_{\mathrm{Ar}}=133 \mathrm{~Pa}$. Therefore, when $P_{\mathrm{Ar}}$ is lower than $20 \mathrm{~Pa}$, sheath thickness of several times $\lambda_{\mathrm{D}}$ becomes much smaller than $\lambda_{\mathrm{c}}$. On the contrary, when the sheath thickness becomes larger than $\lambda_{\mathrm{c}}$ by an increase of pressure, collisions of electrons in the probe sheath cannot be ignored. In this case, usual probe theory has to be modified by taking the electron collision into account.

2) For the RF frequencies $f$ in the range $f_{\mathrm{pi}}<f \ll f_{\mathrm{pe}}(\simeq 1 \mathrm{GHz})$ electrons can completely follow the oscillating electric field in the plasma sheath, but ions cannot follow at all. Here, $f_{\mathrm{pe}}$ is electron plasma frequency. Therefore, nomal sheath in the steady state cannot be formed due to the slow movement of ions at all. When the probe bias voltage $V_{\mathrm{p}}(t)$ is changed rapidly in a DC plasma, ions move under a time-averaged electric field, similar to the case at $\omega t=\pi$ in Figuer 7. As long as RF frequency $f$ is kept in the range $f_{\mathrm{pi}}<f \ll f_{\mathrm{pe}}$, probe characteristics are not changed as known from the experiments in Section 2. Actually, we confirmed the usefulness of this probe analysis even in the RF discharges at frequency of $13.56 \mathrm{MHz}$ ([32] [33] [35]).

\subsection{In the Case of $V_{\mathrm{p}}(t)<V_{\mathrm{s} 0}$}

Temporal variations of potential curves near the probe are drawn schematically in Figure 17(a) when probe voltage $V_{\mathrm{p}}(t)$ oscillates between $V_{\mathrm{p}}+V_{\mathrm{p} 1}$ and $V_{\mathrm{p}}-V_{\mathrm{p} 1}$ around 
$V_{\mathrm{p}}$ in a DC plasma. In the case of $f=30 \mathrm{kHz}$, the inequality $n_{\mathrm{i}}>n_{\mathrm{e}}$ is always estab-

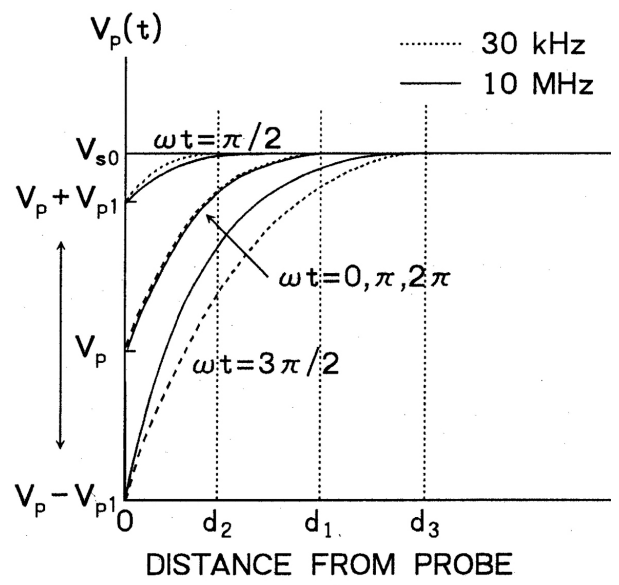

(a)

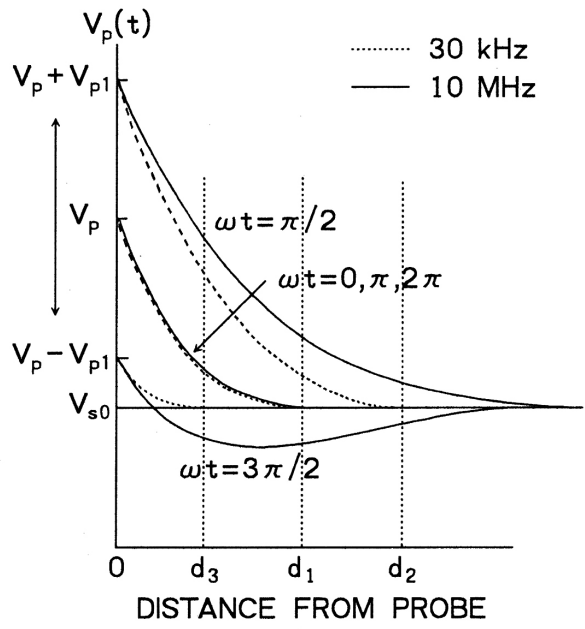

(b)

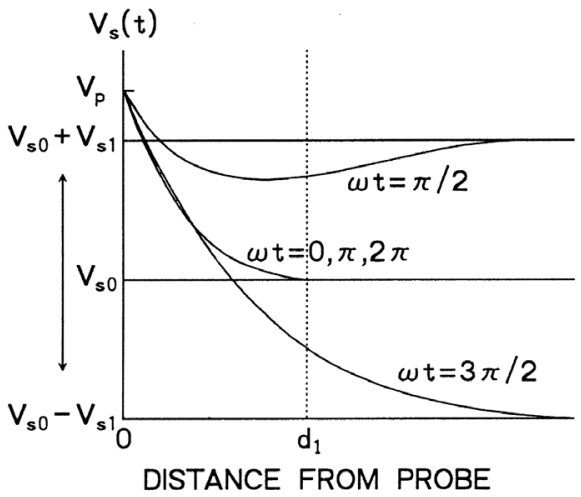

(c)

Figure 17. Schematic of space potential profiles $V_{\mathrm{s}}$ near the probe in the cases of (a) $V_{\mathrm{p}}<V_{\mathrm{s} 0}-V_{\mathrm{p} 1}$ in DC discharge plasmas, (b) $V_{\mathrm{p}}>V_{\mathrm{s} 0}+V_{\mathrm{p} 1}$ in DC discharge plasmas, and (c) $V_{\mathrm{p}}>V_{\mathrm{s} 0}+V_{\mathrm{s} 1}$ in $\mathrm{RF}$ discharge plasmas for $f=30 \mathrm{kHz}$ (dotted lines) and $f=10 \mathrm{MHz}$ (solid lines). In the case of $30 \mathrm{kHz}$, the sheath thickness $d$ vibrates between $d_{2}$ and $d_{3}$ around $d_{1}$. The profiles are drawn on the basis of the results in Figure 16. 
lished inside the ion sheath so that the potential curves are expressed by convex curves as shown by dotted lines. The sheath edges also oscillates between $d_{2}$ and $d_{3}$ around $d_{1}$. The instantaneous probe current is decided by an instantaneous potential difference $V_{\mathrm{s} 0}-V_{\mathrm{p}}(t)$ as given by Equation (2).

When $f$ is $10 \mathrm{MHz}$, the ions cannot follow the change of RF electric field in the probe sheath, so that during the complete cycle, the density distribution of ion is kept as in the steady state, namely with the same distribution at $\omega t=0$. When $V_{\mathrm{p}}(t)=V_{\mathrm{p}}-V_{\mathrm{p} 1}$, only electron density decreases in comparison with that at $\omega t=0$, so that the potential distribution becomes more positive as shown by solid line at $\omega t=3 \pi / 2$. But, the same electron current is obtained as in the case of $30 \mathrm{kHz}$, because it is decided simply by a potential difference $V_{\mathrm{s} 0}-\left(V_{\mathrm{p}}-V_{\mathrm{p} 1}\right)$, according to Equation (2). On the other hand, when $V_{\mathrm{p}}(t)=V_{\mathrm{p}}+V_{\mathrm{p} 1}$, only electron density increases in comparison with that at $\omega t=0$. As the result, the potential distribution becomes more negative compared to that in the case of $30 \mathrm{kHz}$ as shown by solid convex curve at $\omega t=\pi / 2$. Even in this case, the same electron current as in the case of $30 \mathrm{kHz}$ is obtained, because it is also decided by a potential difference $V_{\mathrm{s} 0}-\left(V_{\mathrm{p}}+V_{\mathrm{p} 1}\right)$, according to Equation (2).

In this way it is found that the probe current is independent of the applied frequncy $f$ in the case that $V_{\mathrm{p}}$ is below $V_{\mathrm{s} 0}-V_{\mathrm{p} 1}$. Therefore, it is confirmed that the electron temperatue $T_{\mathrm{e}}$ of RF discharge plasma can be obtained from the semi-log plot of time averaged characteristic curve as shown by opened circles in Figure 4.

\subsection{In the Case of $V_{\mathrm{p}}(t)>V_{\mathrm{s} 0}$}

Potential distributions in the cases of $f=30 \mathrm{kHz}$ and $10 \mathrm{MHz}$ are schematically drawn by dotted and solid lines, respectively, in Figure $17(\mathrm{~b})$. When $f=30 \mathrm{kHz}$, which is lower than $f_{\mathrm{pi}} / 10$, a conventional probe sheath is formed according to the probe potential oscillation between $V_{\mathrm{p}}+V_{\mathrm{p} 1}$ and $V_{\mathrm{p}}-V_{\mathrm{p} 1}$ around $V_{\mathrm{p}}$. Simultaneously, the sheath edge also oscillates between $d_{2}$ and $d_{3}$ around $d_{1}$.

However, when $f=10 \mathrm{MHz}$, which is higher than $f_{\mathrm{pi}}$, the density distribution of ion is always kept as in the averaged state at $\omega t=0$. In this case, an abrupt increase in the probe potential from $V_{\mathrm{p}}$ to $V_{\mathrm{p}}+V_{\mathrm{p} 1}$ between $\omega t=0$ and $\omega t=\pi / 2$ in Figure 6 causes a spread of the effective sheath width, as observed in Figure 16(a), which results in an increase in the electron current, as show in Figure 16(b). This is the reason why the electron current is so much increased at $\omega t=\pi / 2$ in Figure 6. On the other hand, when the probe voltage rapidly decreases from $V_{\mathrm{p}}$ to $V_{\mathrm{p}}-V_{\mathrm{p} 1}$ between $\omega t=\pi$ and $\omega t=3 \pi / 2$ in Figure 6, electron current is suppressed, as observed in Figure 16(b), by a formation of a negative potential dip, as observed in Figure 16(a). This negative potential dip is also formed in front of a cathode of a diode, namely a virtual cathode [40] [41]. This is the reason why the electron current is so much suppressed at $\omega t=3 \pi / 2$ in Figure 6 .

\subsection{In the Case of RF Discharge Plasma}

In the RF discharges, space potential $V_{s}(t)$ oscillates between $V_{\mathrm{s} 0}+V_{\mathrm{s} 1}$ and $V_{\mathrm{s} 0}-V_{\mathrm{s} 1}$ 
around $V_{\mathrm{s} 0}$ under the constant probe voltage $V_{\mathrm{p}}>V_{\mathrm{s} 0}+V_{\mathrm{s} 1}$ as schematically shown in Figure $17(\mathrm{c})$. When the space potential rapidly increases from $V_{\mathrm{s} 0}$ to $V_{\mathrm{s} 0}+V_{\mathrm{s} 1}$ between $\omega t=0$ and $\omega t=\pi / 2$, such an abrupt drop of acceleration voltage for the electrons causes slowing down of electron speed, which causes a stagnation of electrons near the probe, and a resultant formation of a negative potential dip, as observed in Figure 16(a). Then, the electron current is suppressed, compared to the case of $30 \mathrm{kHz}$ as shown in Figure 7. On the other hand, when the space potential rapidly decreases from $V_{\mathrm{s} 0}$ to $V_{\mathrm{s} 0}-V_{\mathrm{s} 1}$ between $\omega t=\pi$ and $\omega t=3 \pi / 2$, such speed-up electrons causes a relative lack of electrons near the probe, which results in an increase in the space potential, and hence resulting in a spread of the sheath width as shown in Figure 16(a). Then, more electrons are collected by the probe and the probe electron current is enhanced compared to the case of $30 \mathrm{kHz}$ as shown in Figure 7.

It is clarified that when $V_{\mathrm{p}}$ is higher than $V_{\mathrm{s} 0}+V_{\mathrm{s} 1}$ in RF discharge plasma, RF current with large amplitude flows into the probe as shown in Figure 7. It is also clear that when $V_{\mathrm{p}}$ is lower than $V_{\mathrm{s} 0}-V_{\mathrm{s} 1}$, the same RF current as shown in Figure 17(a) flows into the probe because it is decided by a potential difference $V_{\mathrm{s}}(t)-V_{\mathrm{p}}$.

\section{Conclusions}

Langmuir probe characteristic curve is examined under an influence of relative oscillating potential difference between the probe and the plasma. Sinusoidal potential $V_{\mathrm{p} 1}$ ranging from $30 \mathrm{kHz}$ to $10 \mathrm{MHz}$ with amplitude $V_{\mathrm{p} 1}$ from $0 \mathrm{~V}$ to $7.5 \mathrm{~V}$ is first applied to the probe in a direct-current (DC) discharge plasma. In the case of low frequency, which is very lower than ion plasma frequency $f_{\mathrm{pi}}$, the time-averaged probe characteristic curve has two inflection points at $V_{\mathrm{s} 0}+V_{\mathrm{p} 1}$ and $V_{\mathrm{s} 0}-V_{\mathrm{p} 1}$. On the other hand, in the case of high frequency which is higher than $f_{\mathrm{pi}}$, there appears two inflection points at $V_{\mathrm{s} 0}$ and $V_{\mathrm{s} 0}-V_{\mathrm{p} 1}$ on a semi-log plot of time-averaged $I_{\mathrm{e}}-V_{\mathrm{p}}$ curve. Upper inflection point coincides with the space potential $V_{\mathrm{s} 0}$ of DC discharge plasma, which is the same space potential at $\omega t=0, \pi$ and $2 \pi$ of the time-resolved $I_{\mathrm{p}}-V_{\mathrm{p}}$ curve. Electron saturation current at upper inflection point well coincides with that of $V_{\mathrm{p} 1}=0 \mathrm{~V}$. Therefore, electron density can be derived from the electron saturation current at the upper inflection point. Potential difference between upper and lower inflection points on a semi-log plot of the time-averaged $I_{\mathrm{e}}-V_{\mathrm{p}}$ curve shows the amplitude $V_{\mathrm{p} 1}$. It was also confirmed that the electron temperature $T_{\mathrm{e}}$ is constant regardless of the frequency $f$ and the amplitude $V_{\mathrm{p} 1}$.

These results are applied to RF discharge plasma with oscillating space potential to measure the plasma prameters by using a DC-biased Langmuir probe. As a result, it was confirmed that similar probe characteristic could be obtained in RF discharge plasmas. The amplitude of space potential oscillation $V_{\mathrm{s} 1}$, obtained from the potential difference between two inflection points on the semi-log plot of the time-averaged $I_{e}-V_{p}$ curve in RF discharge plasmas, was confirmed by an emissive probe method. The electron temperature $T_{e}$ in RF plasmas is confirmed by using the ion acoustic wave method. Both electron temperatures are well agreed with each other between 4.2 
$\mathrm{eV}$ to $0.5 \mathrm{eV}$. The mechanism for the electron current enhancement and suppression for $V_{\mathrm{p}}>V_{\mathrm{s} 0}+V_{\mathrm{s} 1}$ in RF plasmas is clarified by the square pulse experiment.

The method using a single Langmuir probe with a semi-log plot of time-averaged $I_{\mathrm{e}}-V_{\mathrm{p}}$ curve is useful and convenient for measuring electron temperature $T_{\mathrm{e}}$, electron density $n_{\mathrm{e}}$, time-averaged space potential $V_{\mathrm{s} 0}$, and amplitude of space potential oscillation $V_{\mathrm{s} 1}$ in RF plasmas with a frequency of the order of $f_{\mathrm{pi}}<f<f_{\mathrm{pe}} / 10$. This technique mitigates a great deal of troublesome measurement of plasma parameters in $\mathrm{RF}$ discharge plasmas.

\section{Acknowledgements}

Authors are indebted to Prof. Noriyoshi Sato, Tohoku University, for his comments and encouragement.

\section{References}

[1] Garscadden, A. and Emeleus, K.G. (1962) Notes on the Effect of Noise on Langmuir Probe Characteristic. Proceedings of the Physical Society, 79, 535-541. http://dx.doi.org/10.1088/0370-1328/79/3/311

[2] Crawford, F.W. (1963) Modulated Langmuir Probe Characteristic. Journal of Applied Physics, 34, 1897-1902. http://dx.doi.org/10.1063/1.1729709

[3] Boschi, A. and Magistrelli, F. (1963) Effect of a RF Signal on the Characteristic of a Langmuir Probe. IL Nuovo Cimento, 29, 487-499. http://dx.doi.org/10.1007/BF02750367

[4] Hershkowitz, N., Cho, M.H., Nam, C.H. and Intrator, T. (1988) Langmuir Probe Charactteristics in RF Glow Discharges. Plasma Chemistry and Plasma Processing, 8, 35-52. http://dx.doi.org/10.1007/BF01016929

[5] Oksuz, L., Soberon, F. and Ellingboe, A.R. (2006) Analysis of Uncompensated Langmuir probe Characteristics in Radio-Frequency Discharges Revisited. Journal of Applied Physics, 99, Article ID: 013304. http://dx.doi.org/10.1063/1.2158496

[6] Braithwaite, N.J., Benjamin, N.M.P. and Allen, J.E. (1987) An Electrostatic Probe Technique for RF Plasma. Journal of Physics E: Scientific Instruments, 20, 1046-1046. http://dx.doi.org/10.1088/0022-3735/20/8/018

[7] Cox, T.I., Deshmukh, V.G.I., Hope, D., Hydes, A., Braithwaite, N.J. and Benjamin, N.M. (1991) The Use of Langmuir Probes and Optical Emission Spectroscopy to Measure Electron Energy Distribution Functions in RF-Generated Argon Plasmas. Journal of Physics D: Applied Physics, 20, 820-831. http://dx.doi.org/10.1088/0022-3727/20/7/002

[8] Annaratone, B.M. and Braithwaite, N. (1987) A Comparison of a Passive (Filtered) and an Active (Driven) Probe for Plasma Diagnostics. Measurement Science and Technology, 2, 795-800. http://dx.doi.org/10.1088/0957-0233/2/8/014

[9] Ohsawa, A., Ohuchi, M. and Kubota, T. (1991) Improved RF-Driven Probe Method for RF Discharge Plasma Diagnostics. Measurement Science and Technology, 2, 801-806. http://dx.doi.org/10.1088/0957-0233/2/8/015

[10] Sudit, I.D. and Chen, F.F. (1994) RF Compensated Probes for High-Density Discharges. Plasma Sources Science \& Technology, 3, 162-168. http://dx.doi.org/10.1088/0963-0252/3/2/006

[11] Dyson, A., Bryant, P. and Allen, J.E. (2000) Multiple Harmonic Compensation of Langmuir Probes in RF Discharges. Measurement Science and Technology, 11, 554-559. 
http://dx.doi.org/10.1088/0957-0233/11/5/316

[12] Wilson, J.L., Caughman, J.B.O., Nguyen, P.L. and Ruzic, D.N. (1989) Measurements of Time Varying Plasma Potential, Temperature, and Density in a $13.56 \mathrm{MHz}$ Radiofrequency Discharge. Journal of Vacuum Science \& Technology A, 7, 972-976. http://dx.doi.org/10.1116/1.575830

[13] Paranjpe, A.P., McVittie, J.P. and Self, S.A. (1990) A Tuned Langmuir Probe for Measurements in RF Glow Discharges. Journal of Applied Physics, 67, 6718-6727. http://dx.doi.org/10.1063/1.345109

[14] Nisha, M., Saji, K., Ajimsha, R., Joshy, N. and Jayaraj, M.K. (2006) Characterization of Radio Frequency Plasma Using Langmuir Probe and Optical Emission Spectroscopy. Journal of Applied Physics, 99, Article ID: 033304. http://dx.doi.org/10.1063/1.2171777

[15] Song, M.A., Lee, Y.W. and Chung, T.H. (2011) Characterization of an Inductively Coupled Nitrogen-Argon Plasma by Langmuir Probe Combined with Optical Emission Spectroscopy. Physics of Plasmas, 18, Article ID: 023504.

http://dx.doi.org/10.1063/1.3554706

[16] Carlson, R.W., Okuda, T. and Oskam, H.J. (1964) Studies of the Dynamic Properties of Langmuir Probes I: Measuring Methods. Physica, 30, 182-192. http://dx.doi.org/10.1016/0031-8914(64)90212-5

[17] Okuda, T., Carlson, R.W. and Oskam, H.J. (1964) Studies of the Dynamic Properties of Langmuir Probes II: Experimental Results, Physica, 30, 193-205.

http://dx.doi.org/10.1016/0031-8914(64)90213-7

[18] Kato, K., Nakagawa, Y. and Sato, N. (1986) Effects on Probe Characteristic of HighFrequency Potential Oscillation. Proceeding of the 41 st Annual Meeting of the Physical Society of Japan, 4, 230.

[19] Kato, K. and Sato, N. (1987) Langmuir Probe Characteristics in Plasmas Involving Periodic Oscillations of Space Potential. Proceeding of the 42nd Annual Meeting of the Physical Society of Japan, 4, 139.

[20] Oskam, H.J., Carlson, R.W. and Okuda, T. (1964) Studies of the Dynamic Properties of Langmuir Probes III: Discussion of the Results, Physica, 30, 375-386. http://dx.doi.org/10.1016/0031-8914(64)90010-2

[21] Dote, T. (1969) A Method for Determining the Plasma Space Potential by an RF Probe. Journal of the Physical Society of Japan, 27, 1640-1647. http://dx.doi.org/10.1143/JPSJ.27.1640

[22] Kemp, R.F. and Sellen, J.M. (1966) Plasma Potential Measurements by Electron Emissive Probes. Review of Scientific Instruments, 37, 455-461. http://dx.doi.org/10.1063/1.1720213

[23] Smith, J.R., Hershkowitz, N. and Coakley, P. (1979) Inflection-Point Method of Interpreting Emissive Probe Characteristics. Review of Scientific Instruments, 50, 210-218. http://dx.doi.org/10.1063/1.1135789

[24] Wang, E., Hershkowitz, N., Intrator, T. and Forest, C. (1986) Techniques for Using Emitting Probes for Potential Measurement in RF Plasmas. Review of Scientific Instruments, 57, 2425-2431. http://dx.doi.org/10.1063/1.1139088

[25] Lee, D., Ting, Y.H., Oksuz, L. and Hershkowitz, N. (2006) Measurement of Plasma Potential Fluctuations by Emissive Probes in $\mathrm{CF}_{4}$ Radio-Frequency Plasma. Plasma Sources Science and Technology, 15, 873-878. http://dx.doi.org/10.1088/0963-0252/15/4/034

[26] Okuno, Y. and Fujita, H. (1991) Potential Formation near Powered Electrode in RadioFrequency-Driven Discharge. Journal of Applied Physics, 70, 642-644.

http://dx.doi.org/10.1063/1.349666 
[27] Takamura, S., Aihara, S. and Takayama, K. (1971) Interactions between Ion Waves and a High-Frequency Electric Field. Journal of the Physical Society of Japan, 31, 925-934. http://dx.doi.org/10.1143/JPSJ.31.925

[28] Lee, A., Jones, W., Gleman, S.M. and Doucet, H.J. (1976) Ion-Acoustic Waves in Large Radio-Frequency Electric Fields. Physics of Fluids, 19, 557-560. http://dx.doi.org/10.1063/1.861488

[29] Watanabe, S. and Khiet, T. (1979) Ponderomotive Force in Interaction between Ion Wave and High Frequency Electric Field. Journal of the Physical Society of Japan, 47, 1275-1282. http://dx.doi.org/10.1143/JPSJ.47.1275

[30] Teii, K., Mizumura, M., Matsumura, S. and Teii, S. (2003) Time- and Space-Resolved Electric Potentials in a Parallel-Plate Radio-Frequency Plasma. Journal of Applied Physics, 93, 5888-5892. http://dx.doi.org/10.1063/1.1568158

[31] Kato, K., Iizuka, S. and Sato, N. (1994) Electron-Temperature Control for Plasmas Passing through a Negatively Biased Grid. Applied Physics Letters, 65, 816-818. http://dx.doi.org/10.1063/1.112240

[32] Kato, K., Iizuka, S., Gangly, G., Ikeda, T., Matsuda, A. and Sato, N. (1997) Electron and Ion Energy Controls in a Radio Frequency Discharge Plasma with Silane. Journal of Applied Physics, 36, 4547-4550. http://dx.doi.org/10.1143/JAP.36.4547

[33] Iizuka, S., Kato, K., Takahashi, A., Nakagomi, K. and Sato, N. (1997) Negative Hydrogen Ions Produced by Electron Temperature Cotrol in an RF Plasma. Journal of Applied Physics, 36, 4551-4553. http://dx.doi.org/10.1143/JUA.36.4551

[34] Hong, J.I., Seo, S.H., Kim, S.S., Yoon, N.S., Chang, C.S. and Chang, H.Y. (1999) Electron Temperature Control with Grid Bias in Inductively Coupled Argon Plasma. Physics of Plasmas, 6, 1017-1028. http://dx.doi.org/10.1063/1.873342

[35] Kato, K., Emi, J. and Iizuka, S. (2008) Control of Electron Temperature by Varying DC Voltage to a Mesh Grid Blanketed with Thin Film in Plasmas. Journal of Applied Physics, 47, 8565-8569. http://dx.doi.org/10.1143/JJAP.47.8565

[36] Manabe, F. (1990) Features of Plasmas Produced by Pin-Hollow Cathode. Graduation Thesis, Department of Electronic Engineering, Tohoku University, Sendai, 31-33.

[37] Wong, A.Y., Motley, R.W. and D'Angelo, N. (1964) Landau Damping of Ion Acoustic Waves in Highly Ionized Plasmas. Physical Review, 133, A436-A442. http://dx.doi.org/10.1103/physrev.133.a436

[38] Chen, F.F. (1974) Introduction to Plasma Physics. Plenum Press, New York, 84.

[39] Chen, F.F. (1974) Introduction to Plasma Physics. Plenum Press, New York, 8.

[40] Fry, T.C. (1921) The Thermionic Current between Parallel Plate Electrodes, Velocities of Emission Distributed according to Maxwell's Law. Physical Review, 17, 441-452. http://dx.doi.org/10.1103/PhysRev.17.441

[41] Langmuir, I. (1923) The Effect of Space Charge and Initial Velocities on the Potential Distribution and Thermoionic Current between Parallel Plane Elctrorodes. Physical Review, 21, 419-435. http://dx.doi.org/10.1103/PhysRev.21.419 
Submit or recommend next manuscript to SCIRP and we will provide best service for you:

Accepting pre-submission inquiries through Email, Facebook, LinkedIn, Twitter, etc. A wide selection of journals (inclusive of 9 subjects, more than 200 journals)

Providing 24-hour high-quality service

User-friendly online submission system

Fair and swift peer-review system

Efficient typesetting and proofreading procedure

Display of the result of downloads and visits, as well as the number of cited articles

Maximum dissemination of your research work

Submit your manuscript at: http://papersubmission.scirp.org/

Or contact jamp@scirp.org 